\title{
THE DUCTILITY OF STRUCTURAL WALLS
}

\author{
T. Paulay* and W. J. Goodsir* *
}

\begin{abstract}
SYNOPSIS
The behaviour of four approximately $\frac{1}{4}$ full size reinforced concrete structural wall models, subjected to cyclic lateral shear load and variable axial compression, is reported. The primary aim of the study was to investigate the mechanism of out of plane instability and the adequacy of existing code provisions with respect to the confinement of critical parts of the flexural compression zones of wall sections that may be subjected during an earthquake to large inelastic displacements. While all units exhibited good energy dissipation properties, failure in the majority of cases occurred suddenly when concrete compression strains resulting from large ductility demands became excessive in the unconfined regions of the wall section. Failure by out of plane buckling was found to occur at a relatively small lateral load, after the buckled region has been subjected in a proceeding cycle to very large inelastic tensile strains. Recommendations are made for improved arrangement of the confining hoop reinforcement in the end regions of wall sections.
\end{abstract}

1.

\section{INTRODUCTION}

The potential for both lateral load resistance and drift control of walls in reinforced multistorey buildings has long been recognised. Relevant early building code provisions (1) were based on assumptions that structural walls which may be subjected to large earthquakes, will possess only limited ductility. Moreover, it was thought that failure would be dominated by shear. Subsequent experimental work $(2,3,4,5)$ and theoretical considerations $(6,7)$ have shown however, that with appropriate detailing of the wall reinforcement and the application of capacity design principles (8), large displacement ductilities combined with excellent energy dissipation may be achieved. The existing provisions of NZS 3101:1982 (8) are based in this latter premise. Consequently a reduced lateral load resistance in multistorey buildings with ductile structural walls, comparable to that of buildings with ductile frames only, could be accepted (9).

Some of the more important aspects of the seismic design of ductile structural walls are summarized in the commentary of NZS 3101:1982 (8) and described elsewhere (7). It is emphasised that inelastic response should be controlled by flexural deformations in a potential plastic hinge, normally at the base of a wall. Other design requirements have been formulated (8) in such a way that adequate rotational ductility may be assumed by the designer to be available. Specific code requirements intend to ensure that the shear strength of a wall will be a little in excess of the

* Professor of Civil Engineering, University of Canterbury, Christchurch, New Zealand.

**Graduate Student, Department of Civil

Engineering, University of Canterbury, Christchurch, New Zealand. largest probable shear demand, that a premature and brittle failure due to crushing of the concrete in the flexural compression zone of wall sections will not occur, that the chosen wall geometry will not encourage lateral instability in the potential plastic hinge region and that individual bars of the principal flexural reinforcement can repeatedly sustain large reversable strains without buckling.

There are two particular features of inelastic wall response for which, at the time of drafting NZS 3101:1982, there were no guidelines available from the technical literature. The first issue was the adequacy of the provisions for the prevention of premature inelastic instability of thin walled sections in the potential plastic hinge region. The second concern stemmed from the arrangement and quantity of transverse hoop reinforcement necessary to provide adequate confinement in the flexural compression zone of wall sections.

As part of a study of the design of interacting frame-wall structures for seismic actions (10), the above two features were also examined in the experimental part of the program. The primary purpose of this paper is to report on the major findings of this project, relevant only to the above two issues, and to make recommendations for improved design.

\section{THE CURRENT APPROACH TO THE DESIGN OF DUCTILE STRUCTURAL WALLS}

In the following, some aspects of the design of structural walls in accordance with NZS 3101:1982 are summarized. This review is restricted to slender cantilever walls. These are characterized in NZS 4203:1976 by a structural type factor of $\mathrm{S}=1.0$, unless a solitary wall is 
considered, in which case $s=1.2$. In comparison, $S=0.8$ for ductile moment resisting multistorey frames and coupled wall structures. A structural type factor in the range of 0.8 to 1.2 implies an expected maximum displacement auctility demand of 6 to 4 .

Three aspects of the current design approach will be subsequently reexamined in the light of recent experimental evidence obtained (10).

\subsection{The Loading of Individual Walls}

When a number of elastic prismatic cantilever walls of identical height provide the total resistance, the lateral load assigned to an individual wall is simply proportional to its stiffness i.e. second moment of section area. From first principles, torsional effects due to lateral load are also taken into account (6). Effects of cracking on stiffness should also be considexed $(7,8)$. Accuracy of the elastic lateral load analysis may be improved if stiffness reduction due to shear deformations and anchorage pull-out is also considered (7).

However, in the design the inelastic nature of response of walls, at the development of full strength of the structure with respect to lateral load, is recognized when allowing load redistribution ( 8 ) between walls of a building to take place. This process should not reduce the design load in any one wall by more than $30 \%$ of the level obtained by the elastic analysis (8).

\section{$2.2 \quad$ Flexural Response}

The bending moments so derived from the code (9) specified lateral loading, $\mathrm{M}_{\text {Code, }}$ are then used to obtain from first principles (6) the necessary flexural reinforcement. In this, usual equilibrium and strain compatibility criteria, shown in Fig. 1, are used together with a strength reduction factor of $\phi=0.9$. A rapidly converging trial and error process may be used in which the neutral axis depth $c_{\text {, }}$ shown in Fig. 1, is found so that equilibrium criteria for internal and external forces are satisfied, while it is assumed that the maximum concrete compression strain is $\varepsilon_{\mathrm{C}}=0.003$ (11).

Provisions of NZS 3101:1982 were conservatively formulated in such a way that adequate displacement ductility potential for reinforced concrete components, including walls, may be assumed to be assured. Apart from exceptional cases, the designer is thus not expected to investigate ductility potential.

It was shown for example (7) that a displacement ductility of 4 could be readily achieved in a cantilever wall when the computed neutral axis depth, $c$, does not exceed a critical value, $c_{C}$, which is given by

$$
\mathrm{c}_{\mathrm{C}}=0.10 \phi_{\mathrm{O}} \mathrm{S} \ell_{\mathrm{W}}
$$

where $\phi_{0}$ is the flexural overstrength factor defined as the ratio of the flexural overstrength of the wall, Mo, to $\mathrm{M}_{\text {code }}$, both moments being taken at the base section of the wall, $s$ is the appropriate structural type factor, and $\ell_{\mathrm{w}}$ is the length of the wall. In this derivation a particularly conservative value with respect to wall height to length ratio $\left(h_{\mathrm{W}} / l_{\mathrm{W}}=8\right)$ was used. With the usual assumptions for the length of a plastic hinge, and the critical concrete strain in the extreme compression fibre of the section $\left(\varepsilon_{\mathrm{C}}=0.004\right)$, a curvature ductility demand of the order of 11 was predicted (7) for a displacement ductility of 4. For smaller $\mathrm{h}_{\mathrm{WV}} / \ell_{\mathrm{W}}$ ratios $\mathrm{Eq}$. (I) is particularly conservative and hence, if desired, it may be replaced by

$$
\left.c_{C}=\frac{8.6}{(4-0.75 S)\left(17-h_{W} / l_{W}\right.}\right) \phi_{O} S 2_{W}
$$

\subsection{Confinement of Wall sections}

When the computed neutral axis depth, $c$, exceeds the critical value, $c_{C}$, the outer half of the wall section in compression should be confined (8) using closely spaced rectangular or polygonal closed hoops and supplementary ties, surrounding the longitudinal bars. A large neutral axis depth implies that at the development of the required ductility, concrete compression strains in excess of 0.004 are to be expected.

Line (1) in Fig. 1 illustrates a strain profile which could ensure adequate curvature ductility. In this case $\mathrm{c}_{l}<\mathrm{C}_{\mathrm{C}}$. However, in the presence of significant axial compression, the computed neutral axis depth may be $\mathrm{c}_{2}>\mathrm{C}_{\mathrm{C}}$. Clearly much larger concrete compression strains are required if the same curvature (line (2)) is to be attained as in the previous case (Iine (1)). Therefore in accordance with current code (8) requirements, a length of the wall equal to $0.5 \mathrm{c}_{2}$ is to be confined (8).

As the neutral axis depth, c, increases beyond the critical value, $\mathrm{c}_{C}$, for the same curvature ductility demand, concrete compression strains become also larger. Hence the amount of confining reinforcement should also increase. The appropriate equations for this reinforcement were established by similarity to the confining requirements of potential plastic hinges in columns subjected to axial load and bending, rather than obtained from any experimental evidence. The present knowledge of mechanisms, effects and roles of confinement originates largely from the extensive research carried out over a number of years at the University of Canterbury (12). The parameter $\mathrm{P}_{e} /\left(\mathrm{f}_{\mathrm{C}}^{\prime} \mathrm{A}_{\mathrm{g}}\right)$ appropriate to measure the effect of axial compression on the potential for curvature ductility in symmetrically reinforced rectangular columns, was replaced for the same purpose in wall sections by the parameter $c / l_{w}$.

It should be noted that walls may not be reinforced symmetrically. Moreover wall sections may not be rectangular. Hence for a wall, the value of the neutral axis depth, c, depends commonly on the direction of the applied lateral loading.

With the symbols defined in section 10 , the amount of confining transverse reinforcement required for wall sections (8) is 


$$
\begin{aligned}
A_{s h} & =m s_{h} h^{\prime \prime} \frac{f_{C}^{\prime}}{f_{Y h}}\left(0.5+0.9 \frac{c}{l_{W}}\right) \\
\text { where } m & =0.3\left(\frac{A^{*}}{A_{C}^{*}}-1\right) \text { or } 0.12
\end{aligned}
$$

whichever is greater.

This confining transverse reinforcement must be provided over the height of the potential plastic hinge region, which is assumed to extend above the critical section by $l_{\mathrm{w}}$ or $h_{\mathrm{W}} / 6$, whichever is larger (8). Across the wall, the outer half of the compression zone of the section, shown cross shaded in Fig. 1, is involved.

\subsection{Instability of Thin Rectangular Wall}

When part of a thin wall section is subjected to large compression strains, the danger of premature failure by instability arises (Fig. 1). This may be the case when, due to axial compressive load and/or section geometry, a large neutral axis depth is required in the plastic hinge zone of a wall. The strain profile ( $\left.2^{\prime}\right)$ shown in Fig. 1 is an example. Current design (8) is based on the precept that instability should not be permitted to govern the strength of structural walls that are expected to exhibit considerable ductility during a large earthquake.

In the absence of information on the "compactness" of wall sections, existing code rules (11), relevant to short columns, as well as engineering judgement were used to recommend (8) that in the potential plastic hinge zone generally the ratio of clear height, $\ell_{n}$, to wall width, b, (Fig. I) should not exceed 10. Under mitigating boundary conditions and strain profiles exceptions may be made (8).

\section{THE EXPERIMENTAL PROGRAM}

\subsection{The Aims of Testing}

The primary objective of this study was to examine current code provisions (8) for the prevention of premature inelastic instability and the supply of confining hoop reinforcement in regions subjected to large compression strains. It was hoped that other useful information with respect to overall hysteretic response, shear mechanisms, sources of significant deformations etc. would also be obtained. To this end four wall units, three with rectangular sections and one having a $T$ section, were tested under a fully reversing cyclic lateral load program simulating seismic actions. From the wealth of information obtained only that relevant to the objective of this paper is presented here.

\subsection{The Loading scheme}

To create conditions that might be conducive to lateral instability (Fig. 1) near the base of a multistorey structural wall, the following specimen configuration and loading scheme were chosen. By necessity the approximately $1 / 4$ to $1 / 3$ scale models could not be built to full height.
Therefore only the bottom few storeys of a prototype nedium rise wall were reproducea.

In terms of buckling, the compression zone of a wall was presumed to be particularly critical when after a previous loading history has softened this zone, a significant corpression load in addition to that due to flexure was applied. Therefore a loading scheme, shown in Figs. 2 and 3 was chosen which reproduced such critical conditions, while giving a moment pattern which is representative for a wall of moderate height. Two distinct stages of loading shown in Fig. 2 existed.

Under westward (negative) acting lateral load, the wall base moment was $M_{1}=P_{1} e-V_{1} h_{W}$. For this condition a small axial compression load of $\mathrm{P}_{1} \simeq 0.05 \mathrm{f}_{\mathrm{C}}^{\prime A} \mathrm{~A}$ was chosen. A small neutral axis depth, $c$, and extensive cracking and yielding of vertical bars in the east end of the wall was thus expected. This load combination is not of great research interest, however, because even at large ductilities no major distress in the compressed concrete is expected.

(b) with reversed (positive) direction of the lateral load, the moment pattern, as shown in Fig. 2(b), becomes more representative of that in the lower parts of a prototype cantilever wall. The maximum value of the moment is in this case $M_{2}=P_{2} e+V_{2} h_{w}$, where a larger axial compression force, $\mathrm{P}_{2}=0.20 \mathrm{C}_{\mathrm{C}}^{\mathrm{A}} \mathrm{g}$, was intended to be used. Hence a larger neutral axis depth, c, will need to develop. Before any compression can be transmitted, by the concrete at this stage in the flexural compression zone of the wall, previously formed large cracks must close. This is a condition which was expected to initiate lateral instability, particularly as inelastic displacements increase.

It is this (positive) moment pattern shown in Fig. 2(b), which is of primary interest. The axial load limits chosen for $\mathrm{P}_{1}$ and $\mathrm{P}_{2}$ were considered as being typical of extreme loads in moderately coupled structural walls.

The laboratory assembly of the test unit is compared with an analogous cantilever in Fig. 3. The axial compression load, P, was introduced by a large capacity (Dartec) test machine, which allowed free rotations of both the top and bottom ends of the wall specimen to take place. Some details of the corresponding connections may be seen in Fig. 4.

The lateral load was introduced by means of a double acting hydraulic jack at the top of the wall. The necessary bending moment at the base was simultaneously introduced by means of a massive steel reaction frame, seen in Fig. 4, attached to the base block (foundation) of the test wall. Deflections of the specimen could be measured from an instrument frame (Fig. 4) which allowed the influence of the rotation of the base block to be eliminated. Figure $3(a)$ shows this scheme when no load is applied $(\mathrm{P}=0)$, while Figs. $3(\mathrm{~b})$ and (c) indicate the distortions relevant to positive (westward) and negative (eastward) 


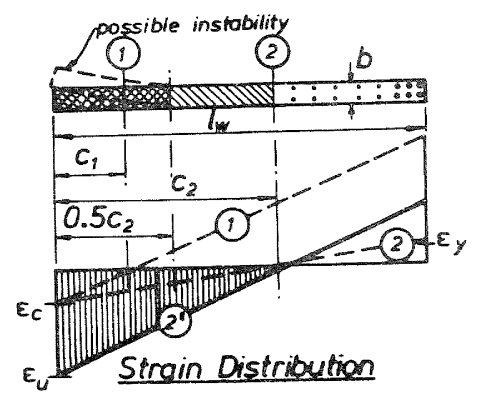

FIG. I Strain Patterns for a Rectangular Wall Section

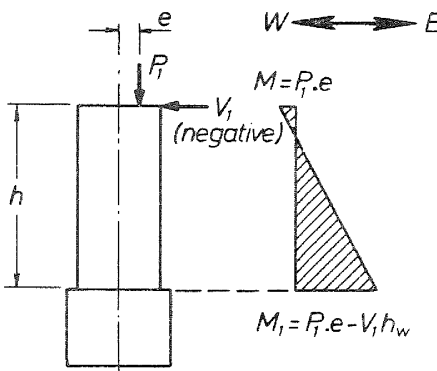

(a)

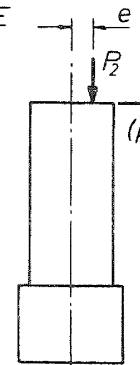

FIG. 2 Bending Moment Patterns Applied to Test Specimens

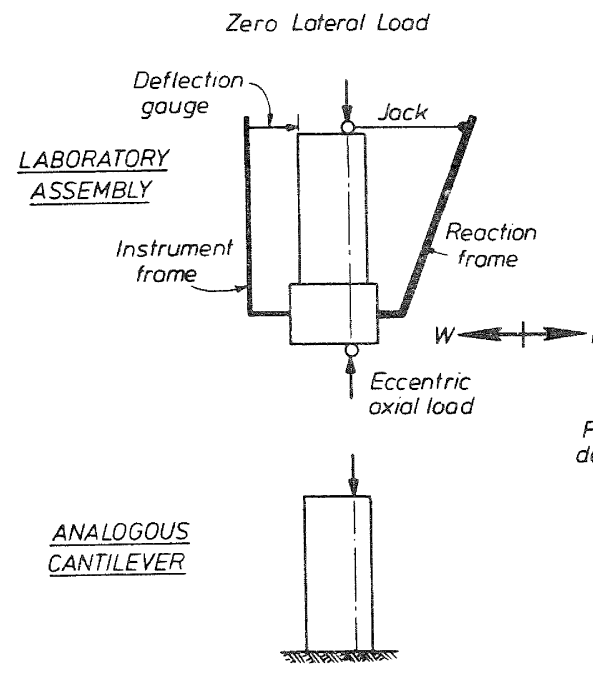

(a)
Positive Lateral Lood (Jock in tension)

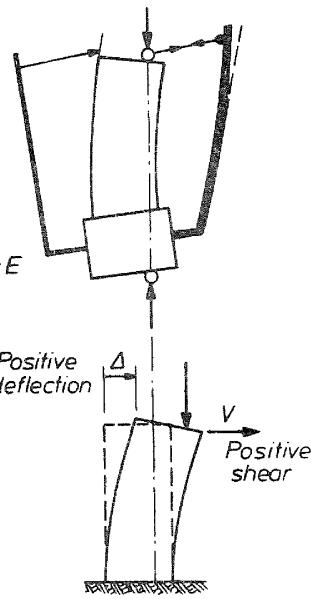

$(b)$
Negotive Lateral Lood (Jock in compression)
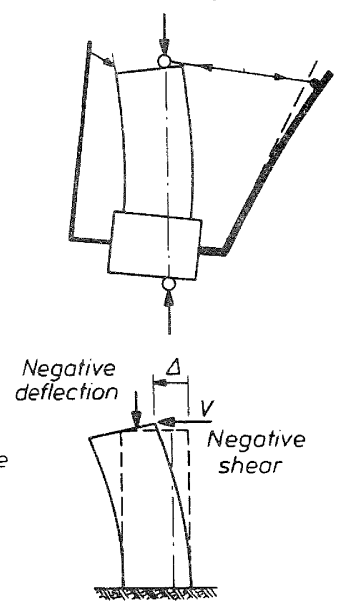

(c)

FIG. 3 Loading Scheme and Sign Convention for Test walls

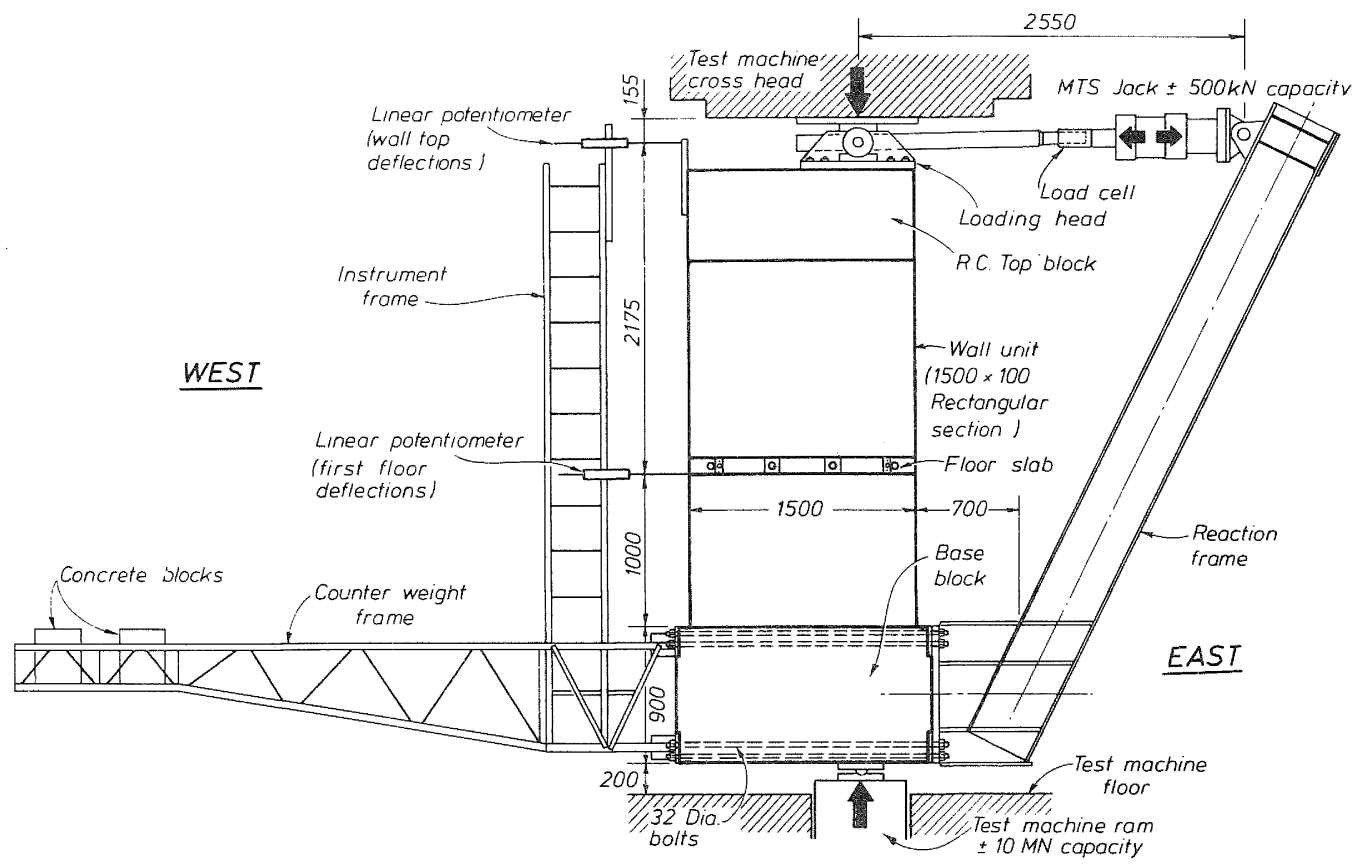

FIG. 4 Elevation of Test Assembly 
TABLE I : GEOMETRY AND REINFORCEMENT CONTENT OF WALI UNITS

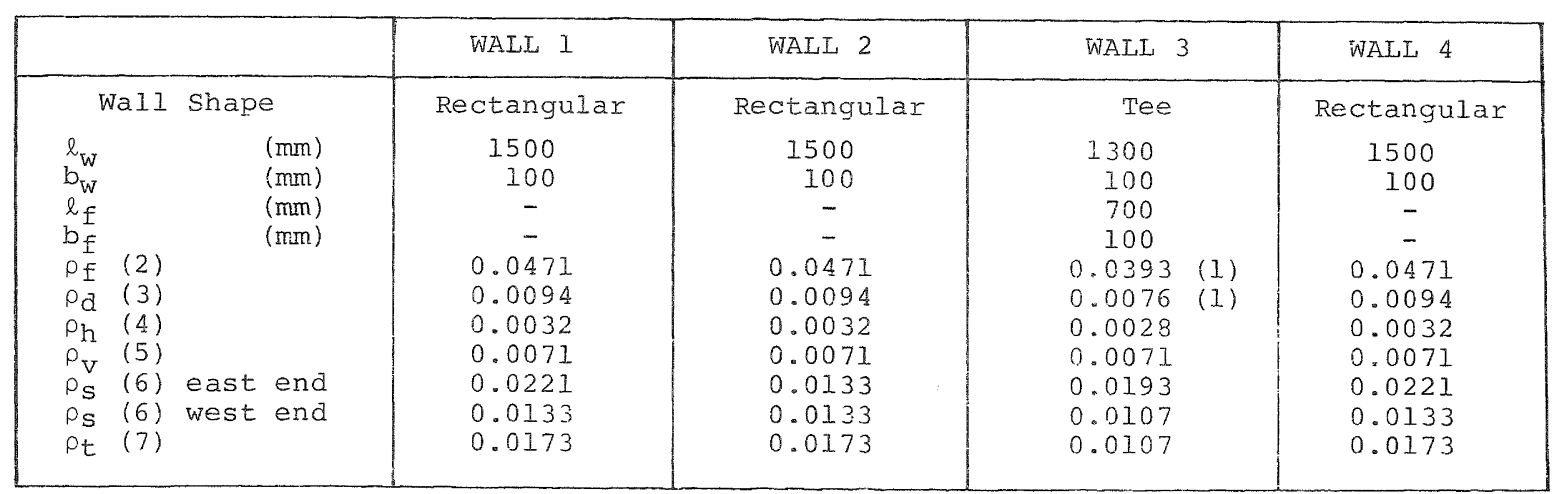

Notes: (I) For east (unflanged) end of wall.

(2) $o_{f}=$ ratio of main flexural reinforcement area to end zone area.

(3) $o_{\mathrm{d}}=A_{\mathrm{S}}$ (end zone) $/ 0.8 l_{\mathrm{W}} \mathrm{b}_{\mathrm{W}}$.

(4) $\rho_{h}=$ ratio of distributed flexural reinforcement area to area of wall web, i.e. $o_{h}=\Sigma A_{b} /\left(b_{W} s_{V}\right)$ where the web bars (of total area $\sum A_{b}$ ) are spaced at $s_{\mathrm{y}}$.

(5) $\rho_{\mathrm{V}}=$ ratio of shear reinforcement area to area of a vertical section of wall. i.e. $\rho_{\mathrm{V}}=\mathrm{A}_{\mathrm{SV}} /\left(\mathrm{sb}_{\mathrm{W}}\right)$ where shear reinforcement of area $\mathrm{A}_{\mathrm{V}}$ is at a spacings.

(6) $\rho_{S}=$ volumetric ratio of hoop reinforcement to confined core.

(7) $\rho_{t}=$ ratio of total vertical wall reinforcement area to total gross section area.

loading of the wall respectively.

Corresponding loads and distortions of the analogous cantilever are seen in the lower part of Fig. 3. The test set up, shown in Fig. 4, was self-equilibrating in terms of lateral load, with no external reactions required. It was developed by Mander (13) for a previous research project.

\subsection{Some Design Considerations and Details}

An attempt was made to keep relative section dimensions in proportion. Realistic materials were used: commercially available deformed bars for the principal flexural reinforcement, plain bars for stirrups and ties, and concrete with $9 \mathrm{~mm}$ maximum aggregate size. No splices were present. The $10 \mathrm{~mm}$ cover to hoops and stirrups in the model was a little larger than the standard. This meant that an excessive proportion of the section was lost on spalling of the cover concrete.

section geometry of the walls and reinforcement contents are summarized in Table I. The strength properties of the materials are given in Table II.

Because of the moment gradient (Fig. 2(b)) in the test set up, it was anticipated that only the bottom storey of the walls would need to have well modelled boundary conditions. Therefore two $100 \mathrm{~mm}$ thick floor slab stubs, one on each side of the wall, were provided at first floor level. The slab was subsequently braced so that at this level no movements, transverse to the plane of the wall, could occur during the test.

\subsection{Construction, Instrumentation and Test Procedure}

First the massive $900 \mathrm{~mm}$ wide base (foundation) block for the $100 \mathrm{~mm}$ wide wall proper was constructed. This was necessary to accomodate a large number of $32 \mathrm{~mm}$ diameter recoverable long bolts required to transmit the tensile forces from the sloping reaction frame (Fig. 4). The strength of the concrete in this foundation block was approximately $20 \%$ greater than that of the concrete in the wall above. The construction joint at the top of the block was treated with a chemical retarder and the coarse aggregate was exposed 24 hours after placing the concrete.

Typical arrangement of the reinforcement in a wall is shown in Fig. 5. Numerous vertical and horizontal bars and some hoop legs were strain gauged. The concrete for the wall was placed in two lifts in plywood formwork with one construction joint above the first flcor, much the same way as in a prototype wall. Finally the top loading block with a prefabricated reinforcing cage and the necessary inserts was concreted.

Potentiometers were used to monitor rotation of the base block, out of plane deformations of the potential buckling zone, vertical displacements for curvature evaluation, shear deformations and gross elongation of the wall at first floor level.

The lateral loading generally followed the pattern used at the University of Canterbury. Two reversing cycles to about $75 \%$ of ideal strength based on measured material properties, were followed by successive displacement controlled fully reversing cycles to nominal displacement ductilities of $\mu_{A}=2,4,6$ etc until failure. These loads were incremented and decremented in stepwise manner within each half cycle. With the exception of Wall l, the axial load intensity was also incrementally varied for each specimen between the extremes of $P_{1}$ and $P_{2}$. Details are given with the description of Wall 2. It is emphasised again that the primary purpose of negative loading was to soften with tension the potential region of buckling. Full details are given elsewhere (10). 
TABLE II : MATERIAL PROPERTIES OF THE WALL UNITS

\begin{tabular}{|c|c|c|c|c|}
\hline & WALL 1 & WALL 2 & WALL 3 & WALI 4 \\
\hline $\begin{array}{l}\text { CONCRETE STRENGTH (1) (MPa) } \\
\text { Base block, lab. cured } \\
\text { Wall, pour 1, lab. cured (2) } \\
\text { pour 2, lab. cured } \\
\text { Top block, lab. cured } \\
\text { Top. cured }\end{array}$ & $\begin{array}{l}35.4 \\
28.6 \\
30.2 \\
26.1 \\
27.5 \\
39.0\end{array}$ & $\begin{array}{l}32.7 \\
25.3 \\
23.2 \\
34.3 \\
30.4 \\
33.9\end{array}$ & $\begin{array}{l}40.3 \\
33.8 \\
29.0 \\
34.2 \\
31.0 \\
40.0\end{array}$ & $\begin{array}{l}39.8 \\
36.5 \\
28.9 \\
27.1 \\
26.4 \\
38.2\end{array}$ \\
\hline $\begin{array}{l}\text { REINFORCEMENT } \\
\text { Main flexural bars - size } \\
f_{\mathrm{y}} \\
\varepsilon_{\mathrm{y}} \\
\text { Yield plateau length }\end{array}$ & $\begin{array}{l}\mathrm{HDl} 2 \\
450 \\
0.0023 \\
4 \varepsilon_{\mathrm{y}}\end{array}$ & $\begin{array}{l}\text { HDl2 } \\
450 \\
0.0023 \\
4 \varepsilon_{Y}\end{array}$ & $\begin{array}{l}\text { HDI0 } \\
400 \\
0.0019 \\
7 E_{Y}\end{array}$ & $\begin{array}{r}\text { HDl2 } \\
345 \\
0.0016 \\
3 \varepsilon_{\mathrm{y}}\end{array}$ \\
\hline $\begin{array}{l}\text { Distributed flexural bars } \\
\text { and shear reinforcement } \\
f_{\mathrm{Y}} \\
\varepsilon_{\mathrm{Y}} \\
\text { Yield plateau length }\end{array}$ & & & $\begin{array}{l}\text { R6 } \\
380 \\
0.0175 \\
6 \varepsilon_{y}\end{array}$ & $\begin{array}{l}\text { R6 } \\
335 \\
0.0015 \\
10 \varepsilon_{y}\end{array}$ \\
\hline $\begin{array}{l}\text { Hoop reinforcement - size } \\
\begin{array}{l}\mathrm{f}_{\mathrm{y}} \\
\text { (MPa) }\end{array} \\
\text { Yield plateau length }\end{array}$ & \multicolumn{4}{|c|}{$\begin{array}{l}\text { R5 } \\
290 \\
0.0014 \\
12 \varepsilon_{y}\end{array}$} \\
\hline
\end{tabular}

Notes: (1) As found from $100 \mathrm{~mm}$ dia. x $200 \mathrm{~mm}$ cylinders tested immediately prior to the testing of the wall units.

The strength of the $100 \mathrm{~mm}$ dia. $\times 200 \mathrm{~mm}$ cylinders is approximately $4 \%$ greater than would have been obtained for standard (6" dia. x 12") cylinders.

(2) Used for theoretical strength calculations.

4. EXPERIMENTALLY OBSERVED BEHAVIOUR

\subsection{Wall 1}

The first unit intended to represent a rectangular wall with rather large axial compression. Its performance is reported in greater detail. Walls 2 and 4 are modifications of this unit, hence the description of their behaviour will be only brief.

\subsubsection{Specimen properties}

The nominal axial compression loads, $\mathrm{P}_{1}$ and $\mathrm{P}_{2}$ (Fig. 2), used in the design and to be applied with an eccentricity of $0.25 \mathrm{l}_{\mathrm{w}}=375 \mathrm{~mm}$ were $0.05 \mathrm{f}_{\mathrm{C}}^{\prime} \mathrm{Ag}$ and $0.30 \mathrm{f}_{\mathrm{C}}^{\prime} \mathrm{Ag}$ For the large axial load, the required $(8)$ confining reinforcement in the east end of the wall (Fig. 5) consisted of 6 legs of R5 bars at $40 \mathrm{~mm}$ vertical centres over the outermost half of the theoretical

compression block. The neutral axis depth, based on a concrete strength of $\mathrm{f}_{\mathrm{C}}^{\prime}=25 \mathrm{MPa}$ before the wall was constructed, was $c=0.43 h_{w}>c_{C}=0.14 \mathrm{~h}$. Hence the confined length was $0.215 \ell_{\mathrm{w}}$. At the west end of the wall (Fig. 5) 5 legs of R5 bars at $72 \mathrm{~mm}$ vertical centres $\left(6 \mathrm{~d}_{\mathrm{b}}\right)$ were provided to satisfy antibuckling requirements for the principal Dl2 vertical bars. For this case $c=0.21 \mathrm{l}_{\mathrm{W}}$. Hence some confining reinforcement would be required (8) over a length of approximately $0.1 \ell_{\mathrm{W}}=150 \mathrm{~mm}$. The amount provided was sufficient to meet this demand, but in terms of code requirements the hoop spacing $(72>40 \mathrm{~mm})$ was excessive. Details of this reinforcement are shown in Fig. 5.
Axial load for this unit only was applied prior to incremental cyclic lateral loading. It remained constant during positive and negative loadings respectively. Axial load was changed after the lateral load was reduced to zero. The maximum applied load in terms of the measured concrete strength, (Table II) was only $0.26 f^{\prime A}$. It is emphasized that axial compression of this intensity would very seldom be encountered even in coupled structural walls. Thus in terms of concrete compression strains, as they relate to ductility, the loading represents very severe conditions.

\subsubsection{Response of Wall 1 and failure mechanisms}

The overall response of the unit is best traced with the base moment-wall top displacement relationship, shown in Fig. 6 . This shows satisfactory hysteretic response. However, at the beginning of the second cycle to a displacement ductility of $\mu_{\Delta}=4$ and the attainment of approximately $85 \%$ of the ideal strength based on the measured material strength properties, the wall failed in a brittle manner. The displacement ductility is defined in terms of a hypothetical yield displacement $\Delta_{y}$, which is taken as 1.33 times the displacement measured when a moment corresponding with 75\% of the ideal strength, $M_{i}$, was applied. The excess strength developed with $\mu_{\Delta}>2$, as seen in Fig. 6, was due to strain hardening of the vertical wall reinforcement.

As expected, extensive flexural as well as diagonal (shear) cracks developed 


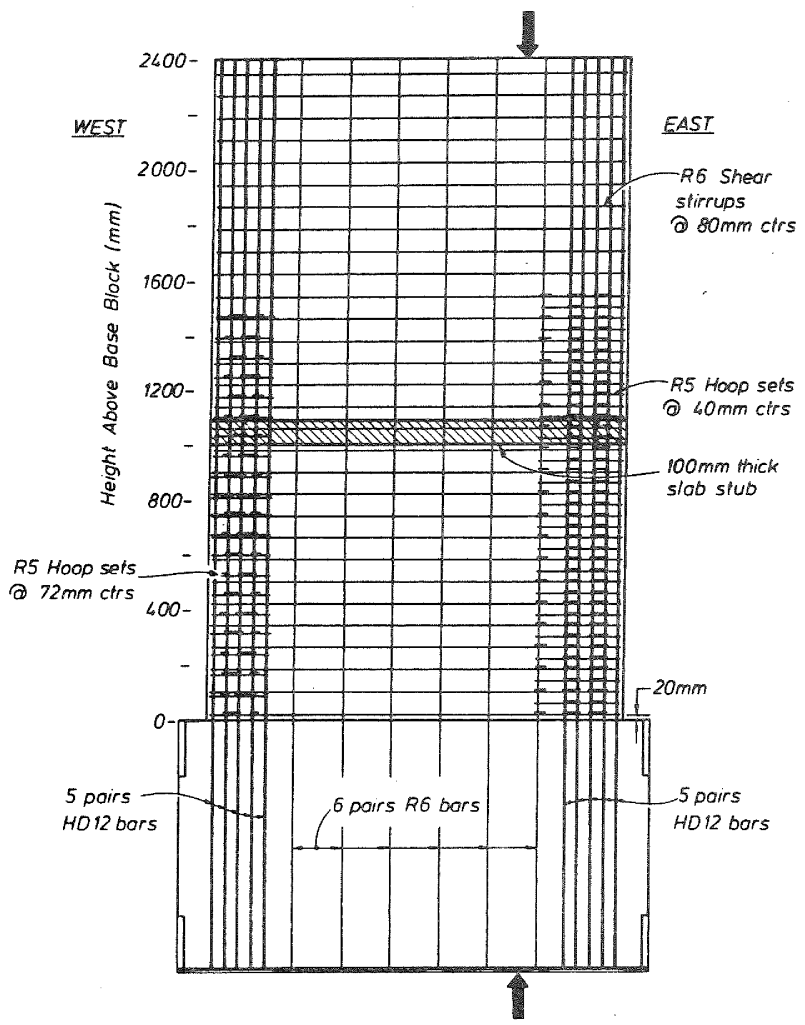

(a) SIDE ELEVATION

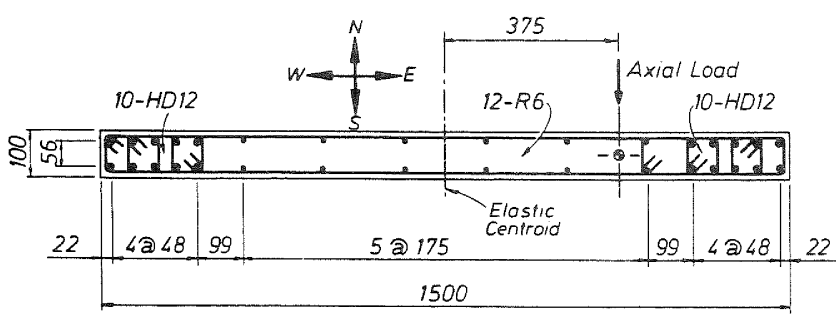

(b) CROSS SECTION

FIG. 5 Reinforcement of Wall 1
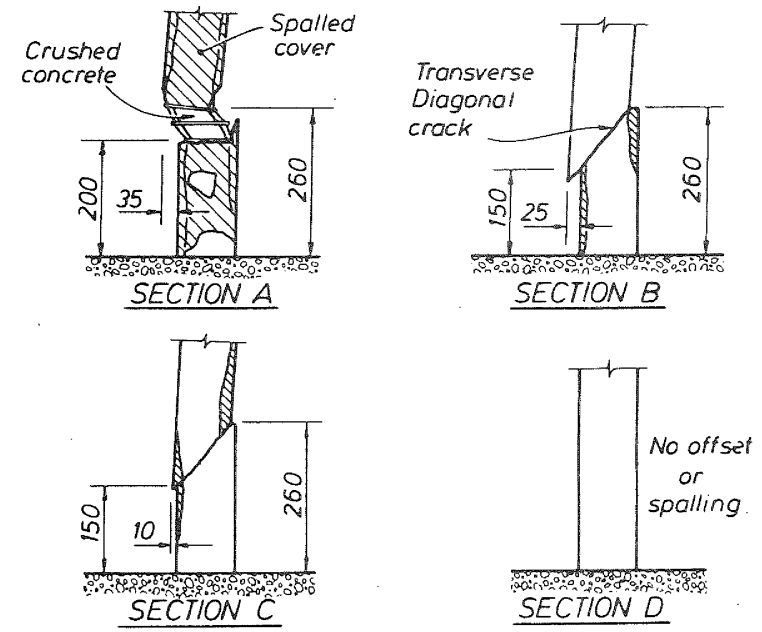

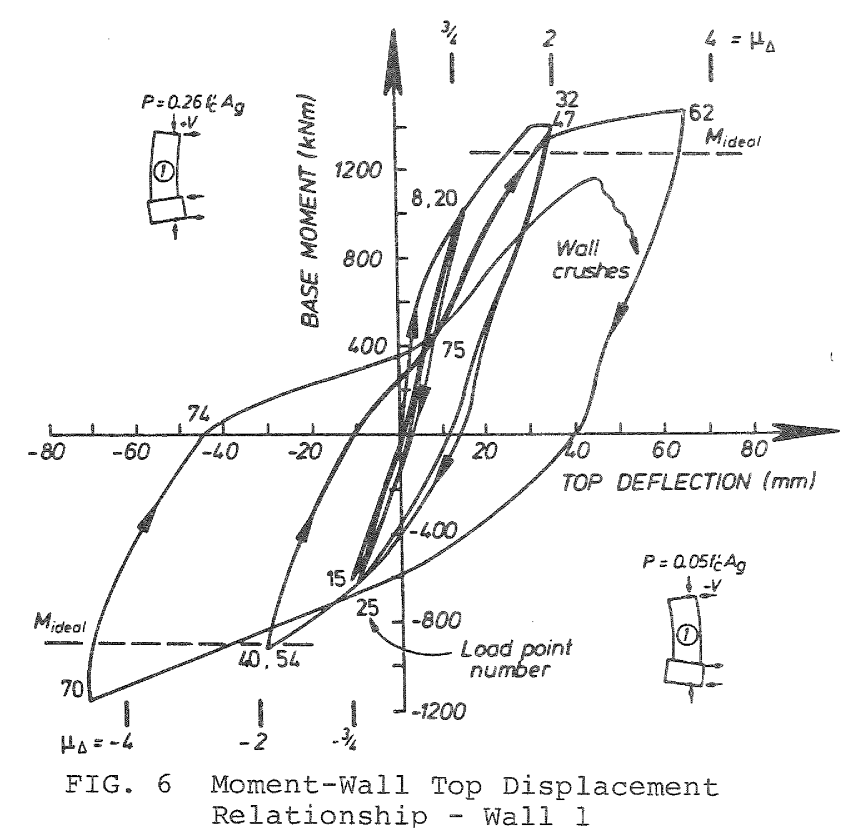

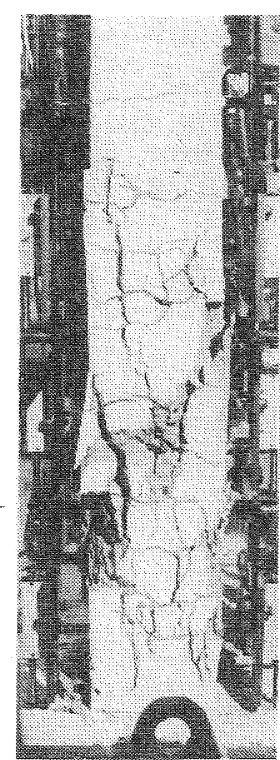

(a)

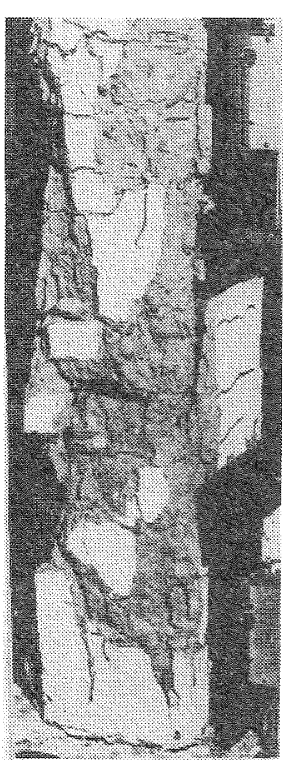

(b)

FIG. 7 East Face of Wall I at Various Stages of Loading

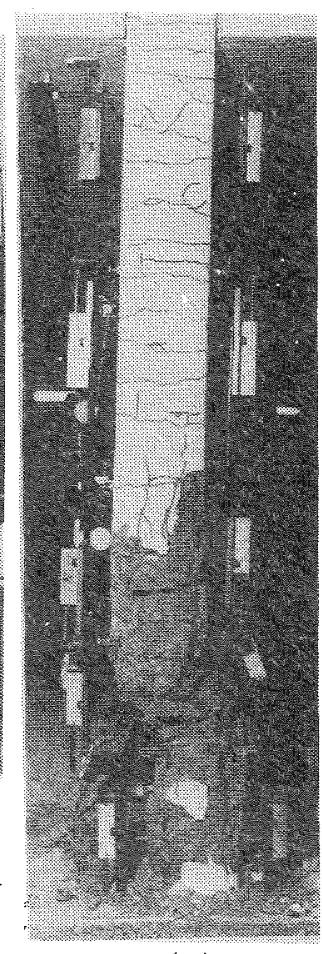

(c)

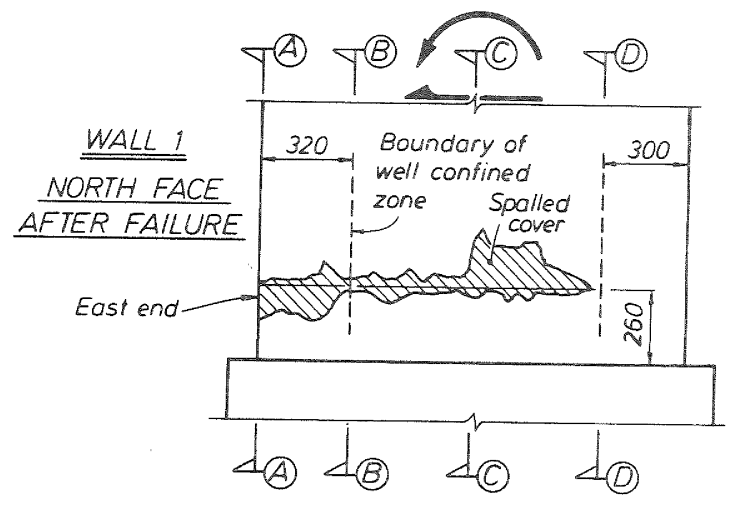

FIG. 8 Features of the Failure of wall 1 
during the first two cycles to a ductility of $\mu_{\Delta}= \pm 2$. Some diagonal cracks reached to the top of the wall. Splitting of the cover concrete commenced at both ends. At increment 47, (Fig. 6), i.e. in the second cycle to only $\mu_{\Delta}=2$, spalling of the cover concrete at the east end, as seen in Fig. 7(a), was evident and this became extensive at load increment 62 when $\mu_{4}=4$ isee Fig. 7(b)). Diagonal cracks at this stage were 3-4 mm wide. It is considered that this was primarily due to the poor bond developed along the horizontal plain bar stirrups. For the same reason the horizontal crack at the base construction joint was much wider $(2-3 \mathrm{~mm})$ at the centre ralf of the section than at the ends where the presence of deformed bars ensured much smaller but correspondingly larger numbers of cracks. In spite of this rather large horizontal crack at the base, no significant sliding occurred when large shearing forces were being transmitted to the base block.

Failure occurred at the commencement of the second cycle to $\mu_{\Delta}= \pm 4$ at a level about $260 \mathrm{~mm}$ above the wall base. It appeared to have been initiated by crushing of the concrete immediately adjacent to the $320 \mathrm{~mm}$ wide confined east end. At load increment 62 compression strains of the order of 0.011 were measured in this region. It is unlikely that such large strains could be attained in an unconfined region a second time without significant loss of strength. Consequently in the second cycles to $\mu_{\Delta}=4$, the neutral axis migrated further towards the tension edge of the wall, while compression strains increased in the confined core at the east end. Failure of the unconfined concrete resulted in diagonal sliding, penetrating also into the confined core, as illustrated in Fig. 8. No hoops fractured. The features shown in Fig. 8 suggest a material failure distinct from lateral instability.

The out of plane displacement history of the potential buckling zone was of primary interest, and this is shown in Fig. 9. Potentiometer readings, shown as dots, were made at $150 \mathrm{~mm}$ from the east face at two levels at each load increment as testing progressed. Deformations are clearly periodic, albeit slightly different at the two levels shown in Fig. 9. Southward lateral movement was associated with negative lateral load. As is seen, displacement amplitudes increased with imposed ductility level but remained reasonably constant between successive cycles to the same ductility. The prefailure lateral displacement (load point 75) was only of the order of $0.3 \%$ of the height of the first storey. The mechanism of lateral sway is discussed in greater detail in section 5 .

Several other features of the wall response were observed, but by necessity they cannot be reported here. Significant values of load and deformation for each specimen are, however, summarised in Table III.

\section{$4.2 \quad$ Wall 2}

To examine the adequacy of the amount of transverse confining hoop reinforcement, it was intended originally to load this wall the same way as the previous one using a reduced amount of confining reinforcement in the case end. In view of the performance of Wall 1, however, it was decided instead to reduce the maximum axial compression to about $0.15 f_{\mathrm{C}}^{\prime} \mathrm{A}_{\mathrm{q}}$. As mentioned earlier axial compression during the test was changed step wise with the lateral load. This eliminated the large and unrealistic displacements that occurred during the testing of the previous unit at zero lateral load when large changes in the eccentric axial load were made. The gradual change of the axial load simulates conditions that might be expected in a coupled wall structure.

\subsubsection{Specimen properties}

Details of external geometry were the same as those of Wall' l shown in Fig. 5. The transverse hoop reinforcement used in both end regions of the wall was the same as that at the west end of Wall 1. This satisfied the antibuckling requirements (8) and was only a little less than that needed for confinement of the east end under the reduced axial compression load. However, the vertical spacing of hoops $(72 \mathrm{~mm})$ was well in excess of that specified by the code $(40 \mathrm{~mm})$.

The axial load, in terms of the actual concrete strength shown in Table II, varied between 0.04 and $0.16 \mathrm{f}^{\prime} \mathrm{A}$, with $0.10 f_{C}^{\prime} A_{g}$ compression applied at ${ }^{\prime}$ zero lateral load. In proceeding from one load point to the next, the axial load adjustment was made prior to the gradual increase of lateral load.

The theoretical neutral axis depth from the east end of the wall section was in this case $\mathrm{c}=0.27 \ell_{\mathrm{W}}>\mathrm{C}_{\mathrm{C}}$.

\subsubsection{Response of Wall 2 and failure mechanism}

The base moment-wall top lateral displacement relationship, showing the overall response of this unit, is presented in Fig. 10. Excellent behaviour was exhibited till the beginning of the third cycle to a nominal displacement ductility of 6 , when a buckling failure occurred. Little degradation of strength or stiffness was evident in the second cycle at a given ductility. The predicted flexural strength, Mideal, was consistently attained and exceeded in both directions due to strain hardening.

Figure $11(a)$ shows Wall 2 after the test when instruments had been removed. Apart from the crushed region, the crack pattern developed at the early stages of the loading hardly changed. Cracks increased somewhat in numbers and significantly in widths as displacement amplitudes increased. Typical for all walls tested are the closely spaced horizontal or only slightly inclined cracks at both ends of the wall, as seen in Fig. Il(a), where the principal vertical deformed bars were placed. Diagonal cracks were fewer in number and correspondingly they were significantly wider at maximum imposed displacement amplitudes. It is likely that in the prototype structure, with deformed vertical bars throughout the wall 


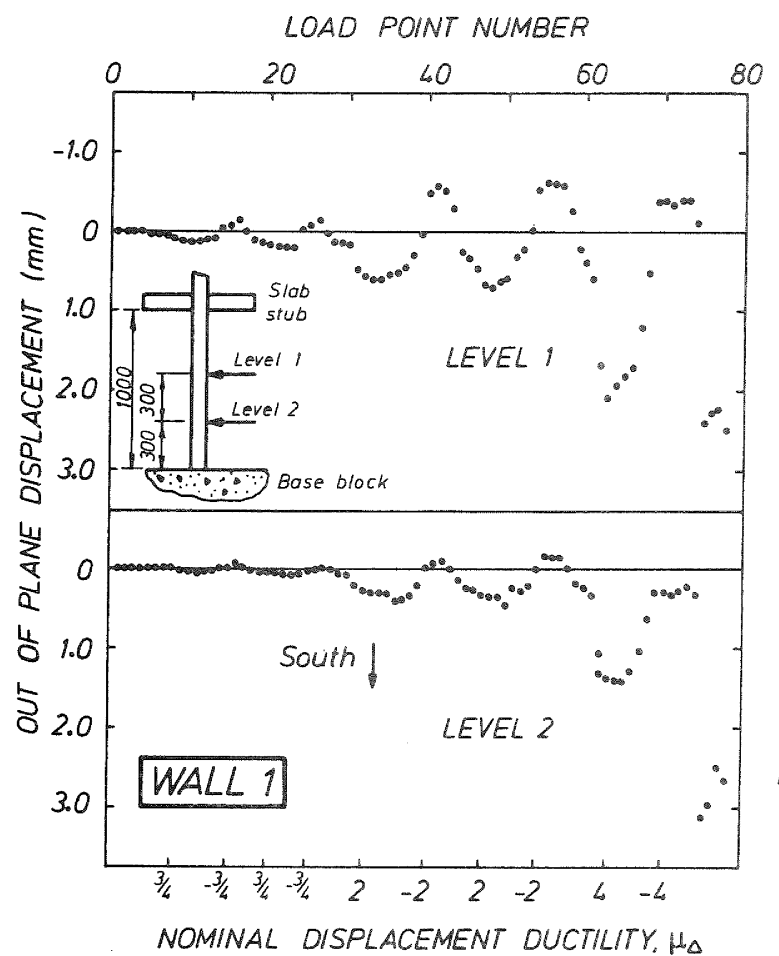

FIG. 9 Out of Plane Displacement History of Wall 1

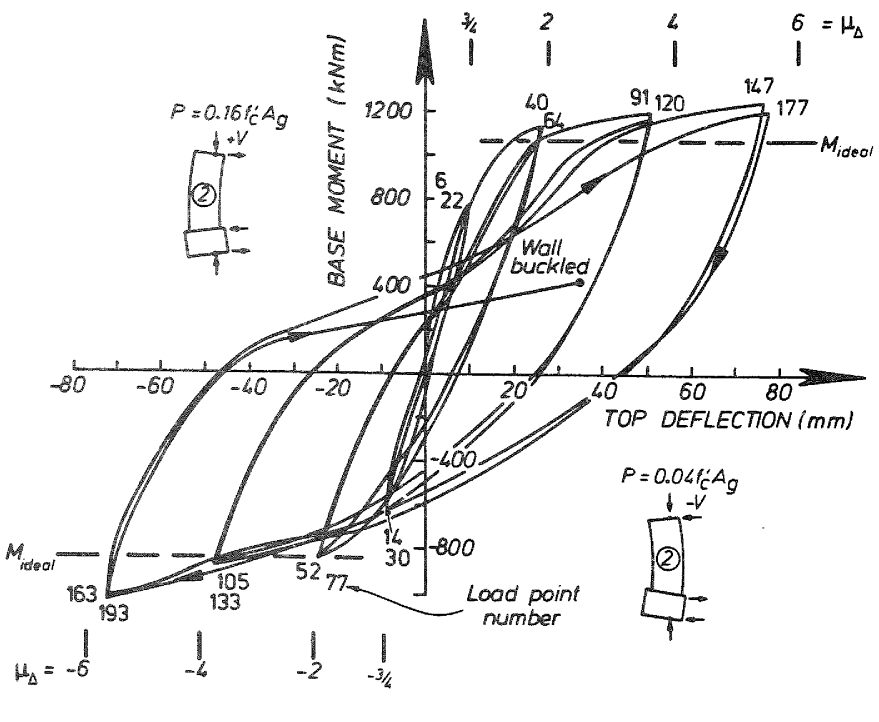

FIG. 10 Moment-Wall Top Displacement Relationship - Wall 2

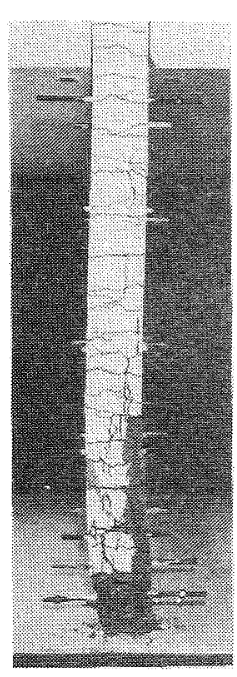

(b)

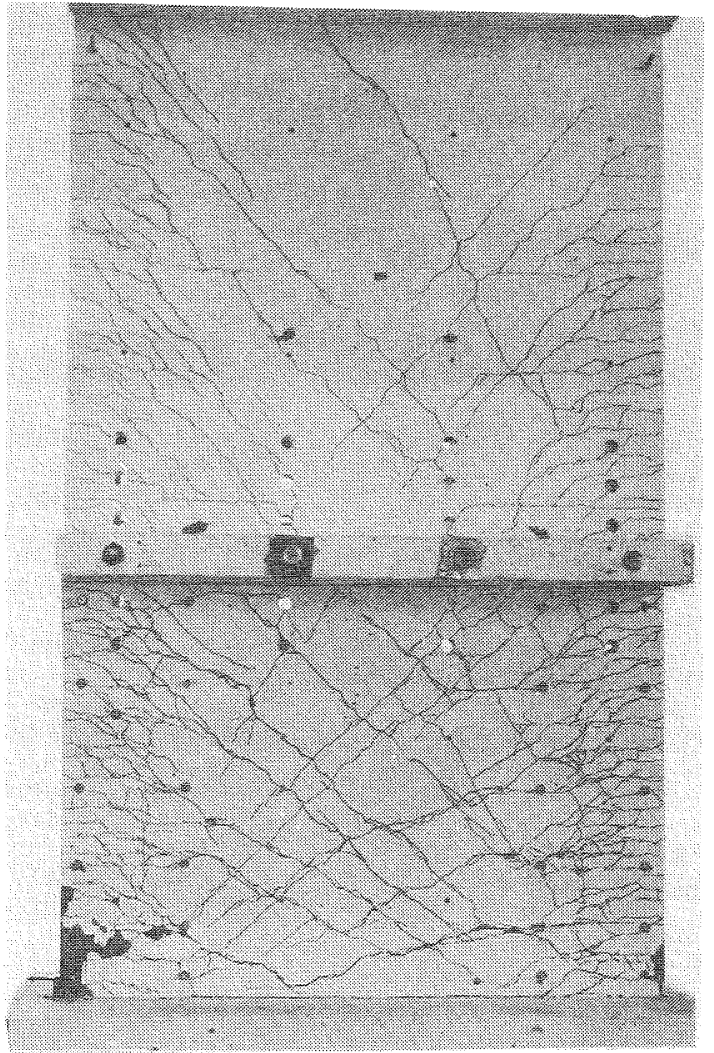

(a)

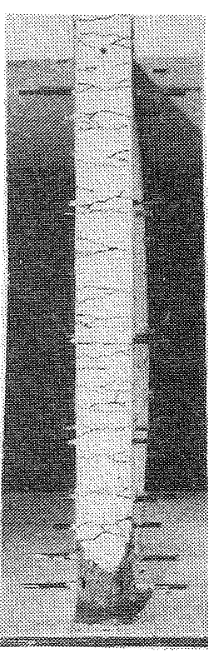

(c)

FIG. 11 The Crack Pattern in Wall 2 (a) After Failure and Views of the (b) East End and (c) West End 
section, the width of diagonal as well as horizontal cracks would be smaller in the centre two thirds of the wall section.

Vertical splitting of the cover concrete extending over $400 \mathrm{~mm}$ from the base at the east end (see Fig. 11(b)) was visible at load point 91. In spite of the base construction joint being $3 \mathrm{~mm}$ wide at this stage $\left(\mu_{A}=+4\right)$, no significant shear slip along this crack was observed. At the beginning of the second cycle to $\mu_{\Delta}=+6$, at load point 177 , horizontal shear displacements of several millimetres were observed across 3-4 mm wide diagonal cracks. Extensive spalling of the cover concrete at the east end and signs of distress of the unconfined concrete adjacent to the confined core were also evident. Failure occurred at a relatively low load, while attempting the attainment $\mu_{\Delta}=+6$ a third time. The mode of failure was lateral instability.

Figure 11 (b) and (c) show end views of the east (buckled) and west ends of the wall after the test. Lateral displacement of the east end occurred over nearly the full height ( $1000 \mathrm{~mm}$ ) between the base and the floor slab, with a maximum displacement of $40 \mathrm{~mm}$ occurring $400 \mathrm{~mm}$ above the base block. A large concentrated transverse rotation occurred at the base. The failure occurred at a relatively low load, without warning. It could have been catastrophic had the applied lateral displacement been increased. Although the unit was severely cracked and extensive spalling had occurred, there was no marked difference in its appearance between the stages at the second cycle to $\mu_{\Delta}=6$ and immediately preceeding failure. It is emphasised that full length buckling of the east end commenced already when the applied axial compression load was approximately $0.05 f_{\mathrm{C}}^{\mathrm{A}} \mathrm{g}$
and before the wall was returned by the horizontal top jack to its original vertical position (Fig. 10). Although some spalling near the base occurred, as Fig. 11(c) shows, the west end of the wall remained straight throughout the test, without showing serious distress.

The out of plane displacement history of the buckled region, measured at $160 \mathrm{~mm}$ from the east edge of the wall, is presented in Fig. 12. Again the response is cyclic, although different in form to that obtained for Wall 1. Lateral oscillation is centred about the initial (vertical) position until the first displacement cycle to $\mu_{\Delta}=4$, after which a southward drift of the east end set in, increasing progressively with larger imposed ductilities.

There are two distinct types of large recurring lateral displacement jumps. The corresponding load points are marked (I) and (II) in Fig. 12. It is seen that the large type (I) southward jumps occurred at moderate axial compression $\left(0.10 f_{C}^{\prime} A_{g}\right)$, when the first increments of lateral load were being applied in the positive direction. At this stage of the loading, axial compression at the east end of the wall becomes sufficiently large to cause closure of the previously formed. cracks. This was due to inelastic steel strains caused by softening because of
Bauschinger effect. After that, lateral displacements reduced and remained sensibly constant while maximum positive ductilities were attained and further while the lateral load was again reduced to zero.

Type II lateral displacements occurred at the attainment of maximum ductilities in the negative direction of loading (Fig. 2), when the east end of the wall was in tension. The tendency of the laterally deformed region to straighten produced a northward displacement. The mechanism of buckling is further examined in section 5 .

\subsection{Wall 4}

In its geometry, instrumentation and reinforcement details, Wall 4 was almost identical to Wall 1 (see Fig. 5). The significant difference resulted from the positioning of the slab stub to reduce the first storey slenderness ratio to 8 to 1 .

\subsubsection{Specimen properties}

The vertical and horizontal shear and hoop reinforcement used was the same as that shown in Fig. 5. The critical east end of the wall with $\mathrm{R} 5$ hoops at $40 \mathrm{~mm}$ centres was adequately confined in terms of code (8) requirements. However, the maximum axial load was reduced to $0.15 f^{A}$. This resulted in a reduced neutral axis depth to $c=0.29 \ell_{W}$. Therefore the confined depth of $326 \mathrm{~mm}$ in the case of Wall 4 covered $75 \%$ of the theoretical compression zone i.e. $50 \%$ more than required by the code ( 8 ).

The axial compressive load was varied stepwise, as in the case of Wall 2, within the limits of 0.03 and $0.15 f_{C}^{\prime} A_{g}$ It was expected that with the reduced slenderness ratio, the onset of lateral instability might be delayed. In addition, with the increased depth of confinement of the flexural compression zone of the wall, it was hoped to prevent an early failure of the unconfined concrete adjacent to the confined end region. A performance superior to that of the previous rectangular units could be anticipated.

\subsubsection{Response of Wall 4 and failure mechanism}

The base moment wall top displacement relationshio for this unit is shown in Fig. 13. In terms of energy dissipation the response of this unit is seen to be very satisfactory. Failure of the wall by crushing of the concrete rather than due to lateral instability occurred when the attainment of $\mu_{A}=6$ in the negative direction was attempted at a second time. In this respect the response of the wall 4 was distinctly superior to that of Wall 1 (with $\mathrm{P}_{1}=0.26 \mathrm{f}_{\mathrm{C}}^{\mathrm{A}}$ ), shown in Fig. 6 . The hysteretic response of Wall 4 is rather similar to that of Wall 2. No explanation could be found, however, for wall 2 with a greater slenderness and a reduced amount of confining reinforcement, being able to sustain another complete cycle to $\mu_{\Delta}=6$. It is to be noted, however, that the maximum displacement (94 mm) imposed at a nominal ductility of $\mu_{\Delta}=6$ in Wall 4, was some $25 \%$ 
larger than that ( $76 \mathrm{~mm}$ ) in the case of Wal.1 2. The absolute value of the displacement at a given ductility factor, even for identical specimens, is sensitive to the chosen value of the yield displacement $\Delta_{y}$. This in turn cannot be determined in experiments with a great degree of accuracy. The intermediate loops, shown in Fig. 13 and applied when moving from large positive to large negative displacements, resulted from the necessity of adjusting the hydraulic jack which had a maximum travel of approximately $75 \mathrm{~mm}$.

Vertical splitting cracks over the entire bottom storey appeared in the east face as early as the first cycle to $\mu_{\Delta}=2$, while similar cracks extended in the west face only $100 \mathrm{~mm}$ above the base when $\mu_{\Delta}=2$. By load joint $79\left(\mu_{\mu}=4\right)$ vertical splitting extended some $300 \mathrm{~mm}$ in the section at both the south and north sides of the east end. While extensive spalling of the cover concrete occurred on reaching load point $159\left(\mu_{\Delta}=6\right)$, lateral displacement of the east end remained relatively small and was without a bias. At load point $184\left(\mu_{A}=-6\right)$ the wall base construction joint crack was $5 \mathrm{~mm}$ wide at the centre of the wall but was less than half this at the east (tension) end. Westward slip at this stage was only of the order of $1 \mathrm{~mm}$. Four major diagonal cracks, each with a width of $3-4 \mathrm{~mm}$, extended within $150 \mathrm{~mm}$ of the west (compression) edge of the wall. A sudden failure of the section occurred when, in the second cycle to $\mu_{\Delta}=6$, the ideal strength was nearly reached. As in the other units, the test at this stage was terminated by the activation of a preset axial displacement trip of the Dartec testing machine.

Figure 14 shows two views of the first storey of this wall after the test. Failure was initiated in the region where the concrete was not confined, some $200 \mathrm{~mm}$ above the base. The compression strain just prior to failure was, at this location, 0.026 . After the failure of this region, the outer confined edge of the wall section became overloaded and it failed in a manner similar to that observed in walls 1 and 3 , as seen in Figs. 7 and 18 . Measured maximum compression strains were of the order of 0.036 in the confined region.

The out of plane movements of the east end of the wall are recorded in Fig. 15. Displacements for this unit were monjtored at four levels. Up till load point 57 ( $\mu_{\Delta}=2$ the second time) readings were very small and are not recorded here. It is seen that movements over the first storey were not consistent. There is no clear correlation between lateral displacement in one direction and the sense of the applied bending moment. From load joint 120 to 140 (from $\mu_{\Delta}=+4$ to $\mu_{\Delta}=-4$ ) little variation in out of plane movement occurred except at level 1. Points at levels 1 and 2 moved southward while levels 3 and 4 moved northward. Lack of consistency is evident even when lateral displacements become significant beyond load point 190. As Fig. 14(b) shows, the final displacement of the lower two levels was towards the south while the upper two levels towards the north. This suggests again that the primary cause of failure of Wall 4 was not via buckling.

\subsection{Wal1 3}

This unit with a $T$ section was loaded so that a relatively large axial force and a positive lateral load produced significant compression in the stem at the eastern end of the section. Negative lateral loading, together with low axial load intensity, ensured a very shallow compression block in the flange and large tensile strains at the east end of the web predisposing this region to instability in subsequent lateral load reversals.

\subsubsection{Specimen properties}

Details of the wall geometry and the reinforcement are shown in Fig. 17. The axial load applied in stepwise manner during the test, based on the measured compression strength of the concrete, was somewhat less than that used in the design, and varied between 0.02 and $0.12 \mathrm{f}^{\mathrm{A}} \mathrm{A}$. The east end of the wall (Fig. 17 (c)) was provided with confining hoop reinforcement over $89 \%$ of the theoretical depth of the compression block. The quantity of hoops was slightly in excess of code (8) requirement. Near the tips of the flange at the western end of the section, only antibuckling ties were provided at $6 \mathrm{~d}_{\mathrm{b}}=60 \mathrm{~mm}$ centres, as shown in Fig. 17. As in the case of wall 1 and 2 , the slab stub, attached in this case to the stem only, resulted in a clear height of $1000 \mathrm{~mm}$ for potential buckling of the east end. The principal details of loads and deformations sustained by all walls are given in Table III. The length of wall 3 was only $1300 \mathrm{~mm}$.

\subsubsection{Response of Wall 3 and failure mechanism}

The performance of the wall, as demonstrated in Fig. 16 by its lateral load response curves, is highlighted only briefly because j.t was very similar to that of Wall 4. Small intermediate load changes were introduced again because of limitations in jack travel. There was good repeatability within cycles to the same ductility. Vertical splitting of the cover concrete at the east end was distinct already at load point $35\left(\mu_{\Delta}=+2\right)$ and spalling extended up to a height of $700 \mathrm{~mm}$ by increment $76\left(\mu_{\Delta}=+4\right)$. Crack widths across the middle of the flange at increment $134(\mu=+5.5)$ were $5-6 \mathrm{~mm}$, becoming 1-2 $\mathrm{mm}$ wide at the edges of the flange where, due to the presence of deformed bars, the spacing of cracks was much smaller (Fig. (Fig. 18(b)). Vertical cracks at the webflange junction did not appear to affect response in any way. Relatively few diagonal cracks developed in the web. However, at increment 159 some of these cracks were $7 \mathrm{~mm}$ wide.

At the beginning of the cycle aimed to achieve nominal ductility of $\mu_{\Delta}=+6$ gross instability was indicated as the bottom $800 \mathrm{~mm}$ of the east end of the wall moved northward. Two increments later, with $\mathrm{P}_{1}=700 \mathrm{kN}=0.12 \mathrm{f}_{\mathrm{C}}^{\mathrm{A}} \mathrm{g}$, the east end stabilised, however, with a distinct southward lateral movement. This axial load was held for some time while readings were made, when suddenly a material compression failure occurred. It is to be noted that the Dartec 


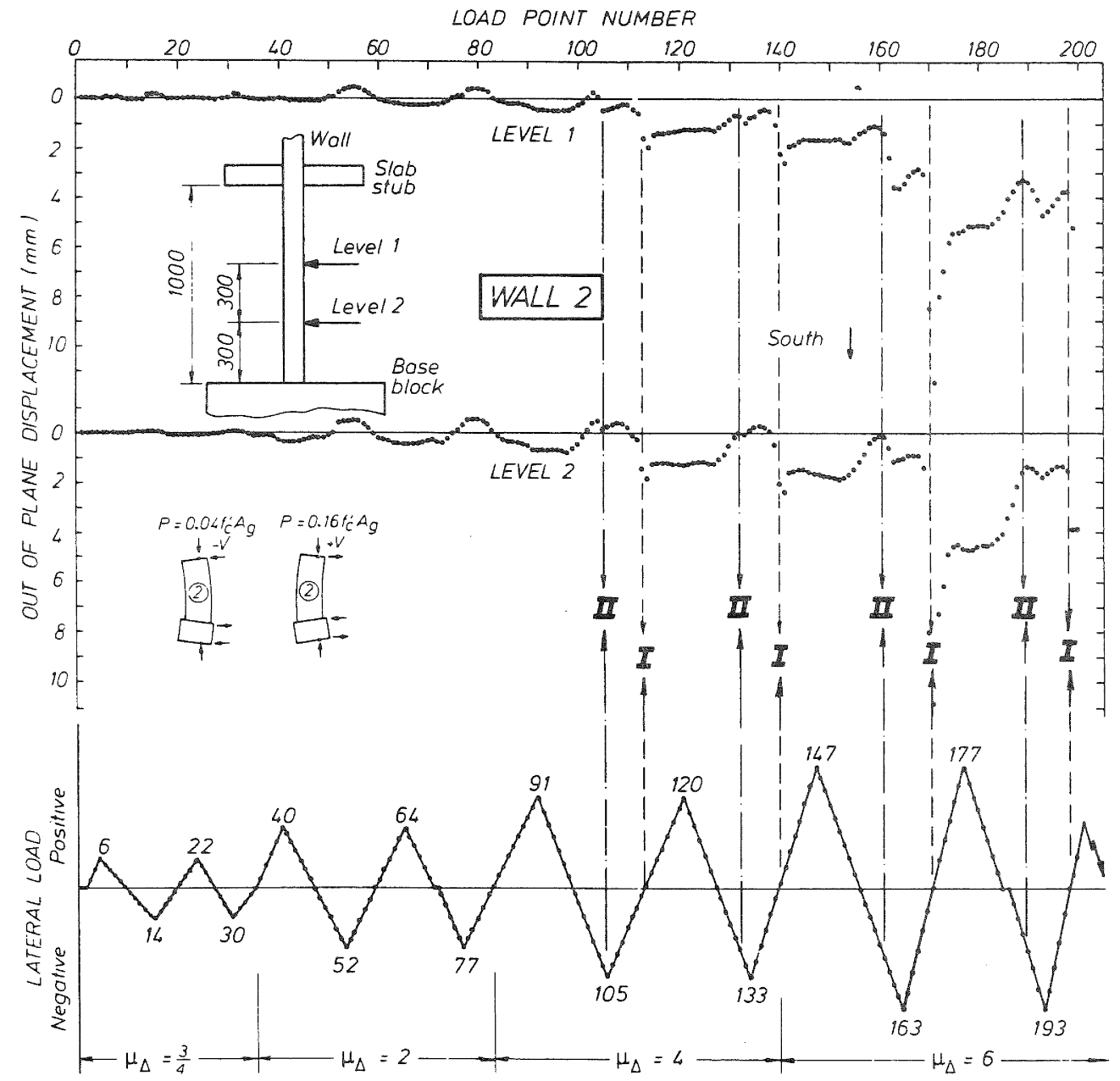

FIG. 12 Out of Plane Displacement History of WaII 2
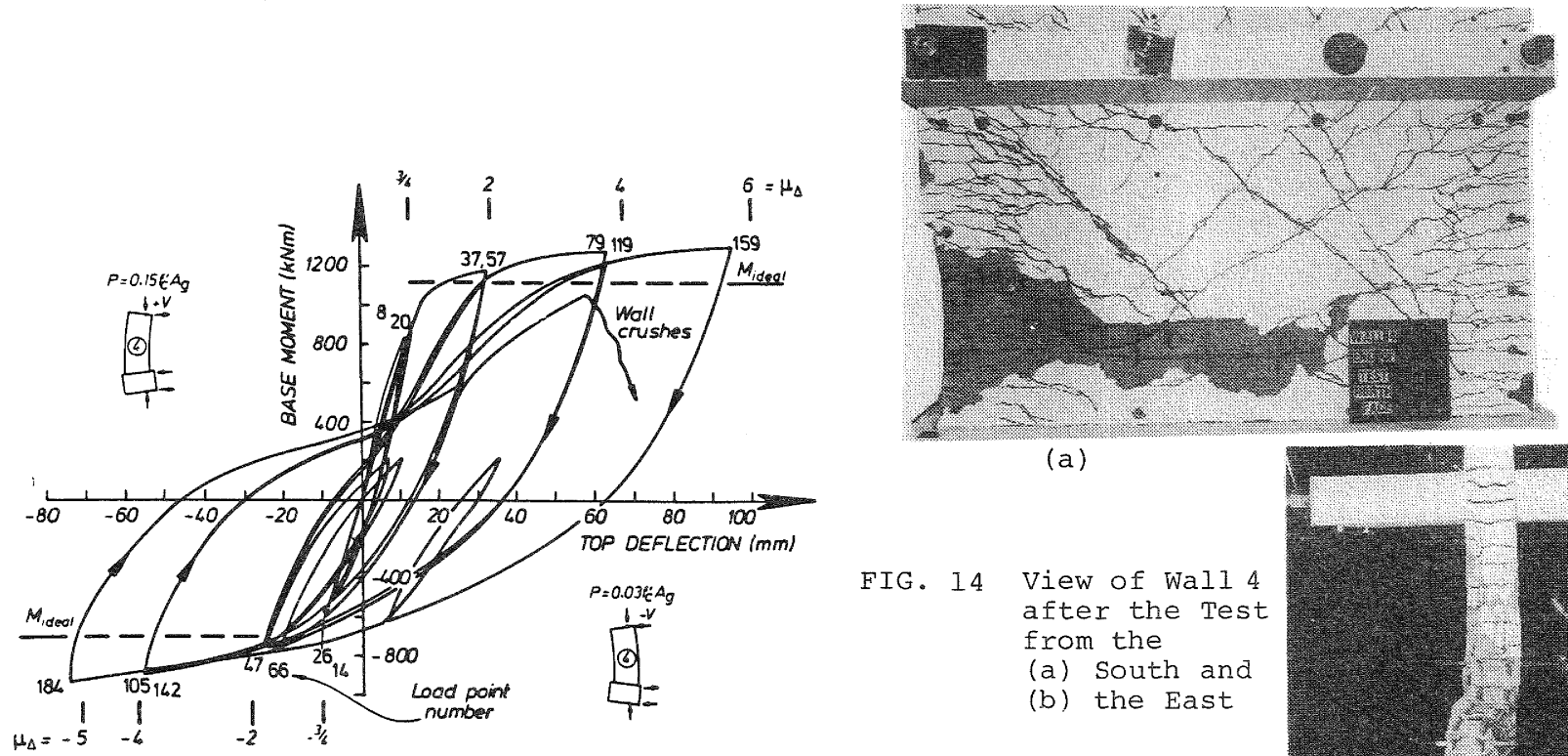

(a)

FIG. I4 View of Wall 4 after the Test from the

(a) South and (b) the East

FIG. 13 Moment-Wall Top Deflection Relationship - Wall 4

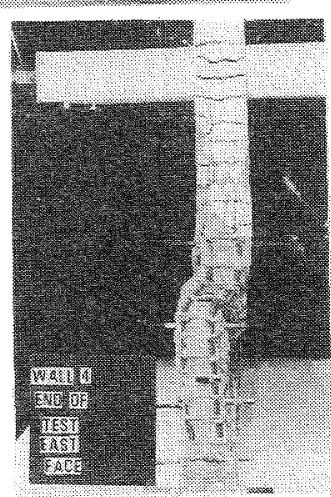

(b) 

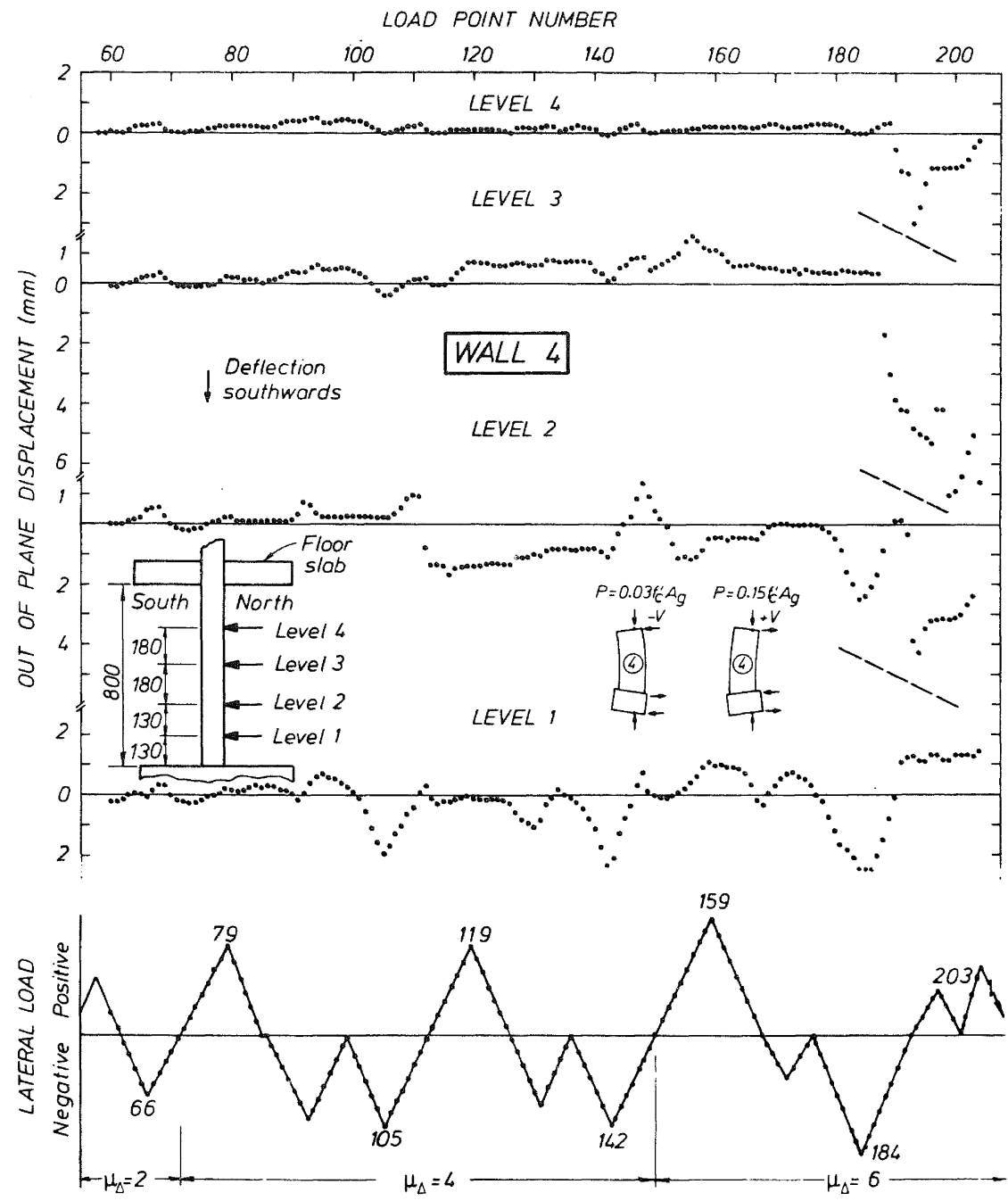

FIG. 15 Out of Plane Displacement History of Wall 4

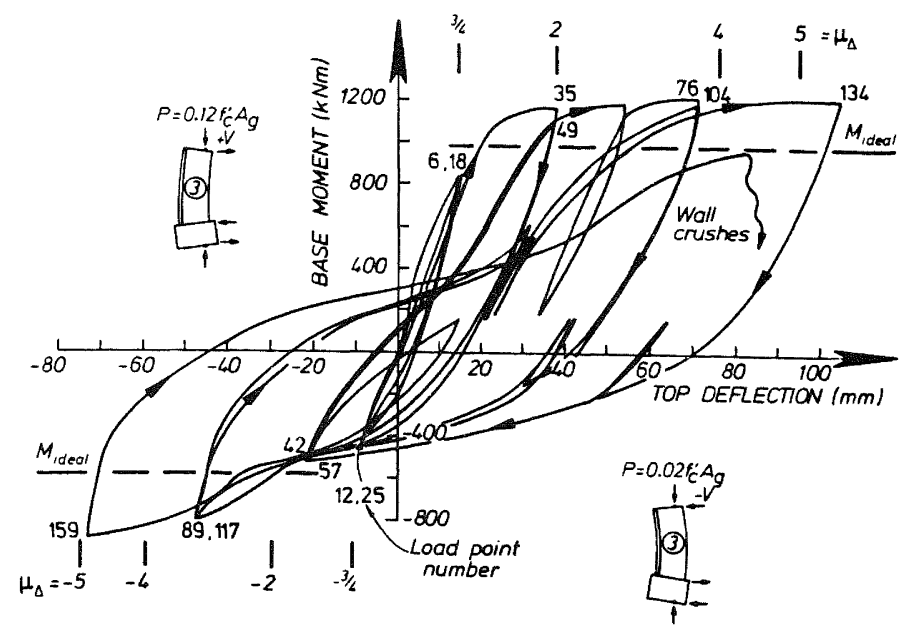

FIG. 16 Moment-Wall Top Deflection Relationship - Wall 3 


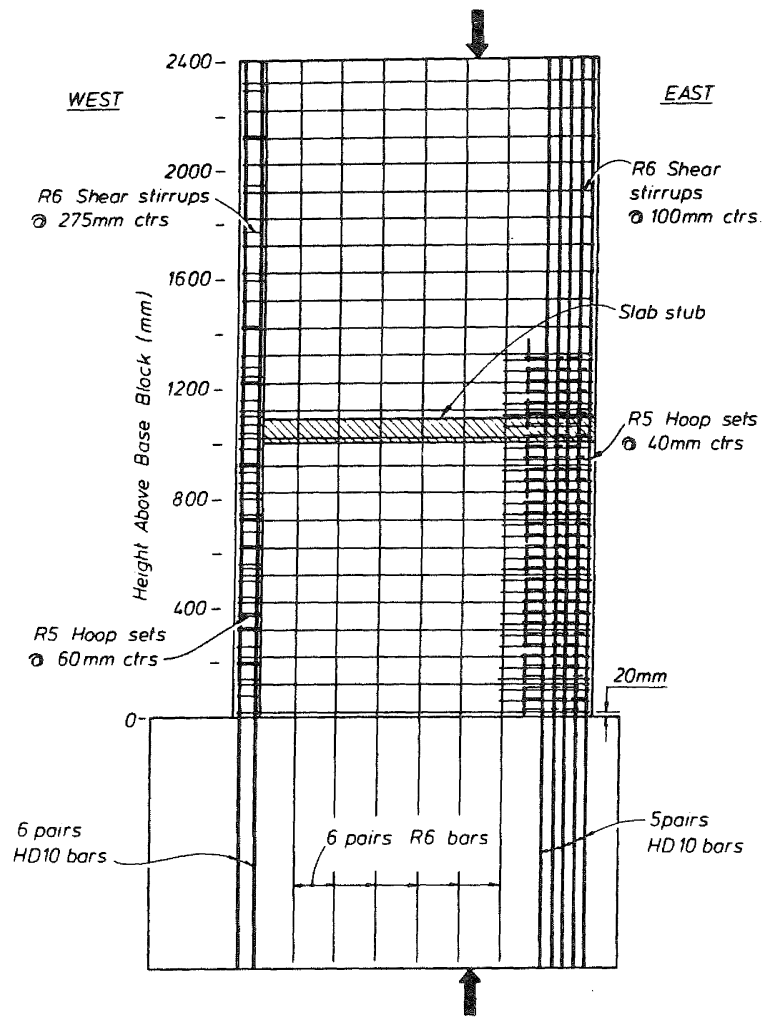

(a) SIDE ELEVATION

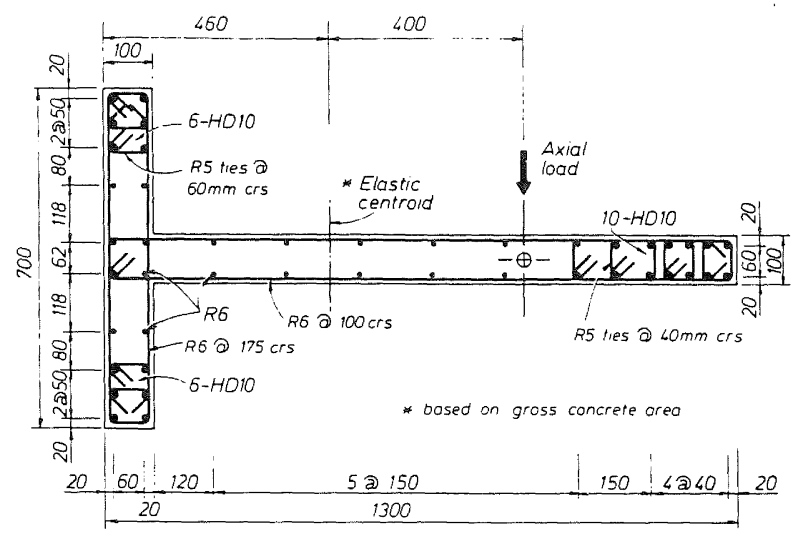

(c) CROSS SECTION

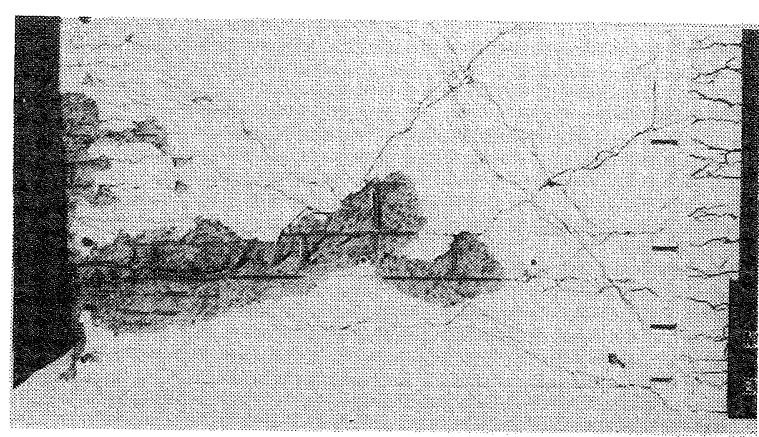

(a)

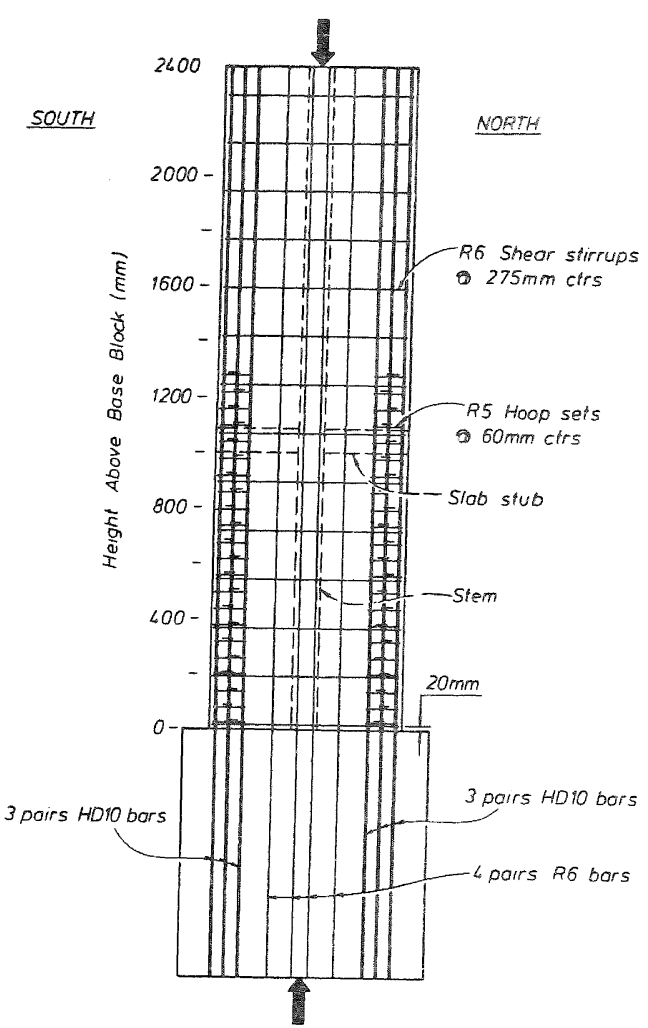

(b) END ELEVATION
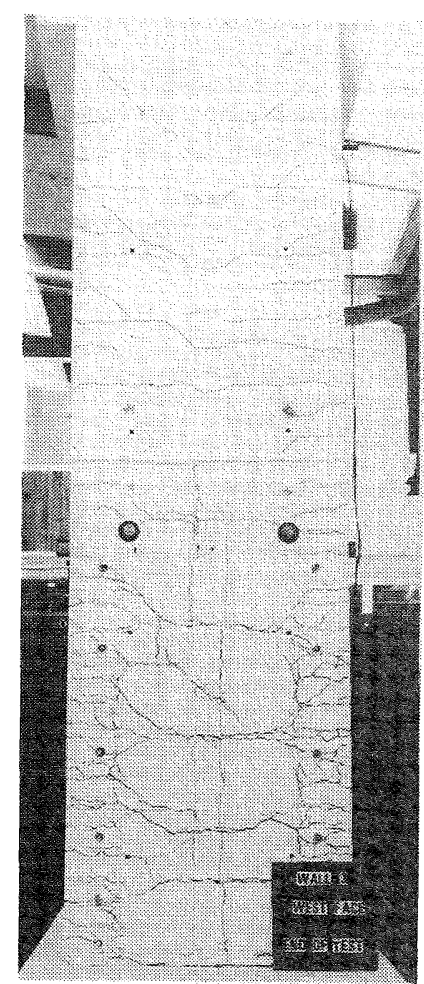

(b)

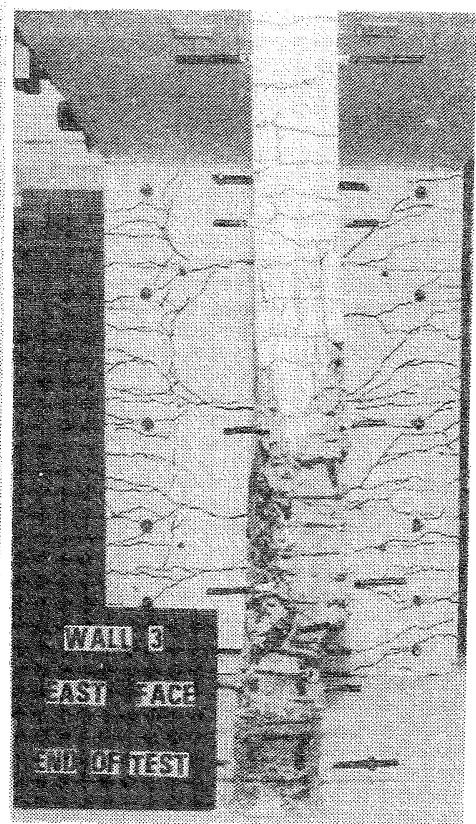

(c)

FIG. 18 Appearance of Wall 3 After Failure Viewed from the (a) North (b) West and (c) East 
TABLE III : SUMMARY OF STRENGTH AND DEFORMATION RESPONSE

\begin{tabular}{|c|c|c|c|c|c|c|c|c|}
\hline \multirow{2}{*}{ Lateral Loading } & \multicolumn{2}{|c|}{ W̄ALL 1} & \multicolumn{2}{|c|}{ WALL 2} & \multicolumn{2}{|c|}{ WALI 3} & \multicolumn{2}{|c|}{ WALI 4} \\
\hline & + & - & + & - & + & - & + & - \\
\hline 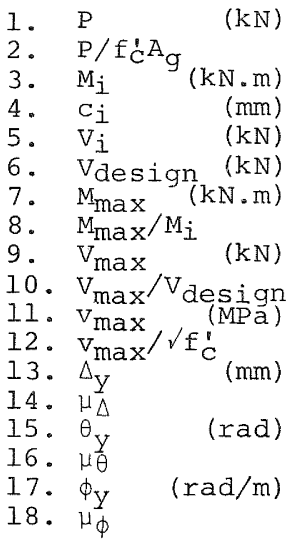 & $\begin{array}{r}1159 \\
0.263 \\
1280 \\
580 \\
266 \\
286 \\
1466 \\
1.15 \\
329 \\
1.15 \\
2.74 \\
0.500 \\
18.0 \\
3.7 \\
0.0036 \\
4.9 \\
0.0020 \\
12.6\end{array}$ & $\begin{array}{c}222 \\
0.051 \\
-897 \\
252 \\
-309 \\
-343 \\
-1158 \\
1.29 \\
-387 \\
1.13 \\
3.22 \\
0.587 \\
-16.0 \\
-4.4 \\
-0.0034 \\
-7.2 \\
-0.0030 \\
-10.7\end{array}$ & $\begin{array}{l}594 \\
0.163 \\
1057 \\
427 \\
263 \\
307 \\
1286 \\
1.22 \\
326 \\
1.24 \\
2.72 \\
0.551 \\
14.0 \\
5.6 \\
0.0039 \\
6.5 \\
0.0022 \\
18.2\end{array}$ & \begin{tabular}{|l}
145 \\
0.040 \\
-839 \\
254 \\
-281 \\
-321 \\
-997 \\
1.19 \\
-340 \\
1.21 \\
2.83 \\
0.575 \\
-13.0 \\
-5.6 \\
-0.0034 \\
-6.3 \\
-0.0022 \\
-9.6
\end{tabular} & $\begin{array}{c}750 \\
0.118 \\
980 \\
383 \\
214 \\
285 \\
1218 \\
1.24 \\
287 \\
1.01 \\
2.76 \\
0.473 \\
19.0 \\
5.5 \\
0.0046 \\
6.6 \\
0.0032 \\
11.3\end{array}$ & $\begin{array}{c}143 \\
0.022 \\
-584 \\
44 \\
-202 \\
-243 \\
-883 \\
1.51 \\
-296 \\
1.22 \\
2.85 \\
0.488 \\
-15.0 \\
-4.9 \\
-0.0026 \\
-6.6 \\
-0.0020 \\
-17.7\end{array}$ & $\begin{array}{c}837 \\
0.153 \\
1114 \\
443 \\
236 \\
326 \\
1294 \\
1.16 \\
307 \\
0.94 \\
2.56 \\
0.423 \\
17.0 \\
5.6 \\
0.0032 \\
8.4 \\
0.0030 \\
11.1\end{array}$ & $\begin{array}{c}152 \\
0.028 \\
-703 \\
192 \\
-241 \\
-344 \\
-916 \\
1.30 \\
-308 \\
0.90 \\
2.57 \\
0.425 \\
-14.5 \\
-5.2 \\
-0.0034 \\
-4.9 \\
-0.0020 \\
-13.3\end{array}$ \\
\hline
\end{tabular}

Notes: 1. Axial load (at wall base section) associated with peak moment.

2. Non-dimensional axial load.

3. Ideal flexural strength, based on measured material properties - see Table II and axial force p-Note (1).

4. Neutral axis position associated with $\mathrm{M}_{i}$ measured from east and west ends of wall for positive and negative lateral loading respectively.

5. Shear force (or lateral force) associated with $M_{i}$.

6. Design shear force.

7. Maximum observed flexural strength.

8. Ratio of $M_{\max }$ to $M_{i}$.

9. Maximum recorded shear force.

10. Ratio of $V_{\max }$ to $V_{\text {design }}$.

11. Maximum nominal shear stress $=v_{\text {max }} /\left(0.8 \ell_{w} b_{w}\right)$.

12. Non-dimensionalized shear stress.

13. Top level yield displacement, estimated from the moment-displacement relationship. $\Delta_{\mathrm{y}}$ values were calculated from the intersection points of best fit lines modelling pre and post-yield response. These lines were constructed by eye.

14. Maximum displacement ductility achieved, i.e. maximum imposed displacement normalised with respect to $\Delta_{y}$.

15. Yield base rotation as determined from the moment rotation relationship (for rotations measured over the bottom storey regions). These may be regarded as plastic hinge rotations only in so far as the plastic hinge length may be taken as first storey height.

16. Maximum rotational ductility.

17. Yield curvature, also as determined from the moment-curvature relationship.

18. Maximum curvature ductility.

testing machine held the vertical load constant and, when necessary, increased the compression strain on the critical section upon reduction of its resistance till ram movement was automatically arrested during failure. At no stage did the flange of the section exhibit signs of distress. Figure 18 shows views of Wall 3 after failure.

Even though the crushing of the concrete in this unit was similar to that seen in Wall 1, (Fig. 7(c)) and Wall 4 (Fig. I4(b)), it was concluded that lateral instability was indirectly responsible for the material failure of Wall 3. With the northward migration of the confined compression zone of the east end of the unit, some compression load was shed to the unconfined regions of the section, necessitating an increase of the depth of the compression zone, i.e. a shifting of the neutral axis to the west. Prior to failure, compression strains of the order of 0.024 were measured in the unconfined concrete. This mechanism is further discussed in the next section. It appears that the transverse confining effect of the base (foundation) block was sufficient to push the failure section to about $250 \mathrm{~mm}$ above the base. This was similar in wall 1.

Instead of presenting the lateral displacement history of this unit, the lateral displacement profiles at distinct stages of the loading history are given in Fig. 19 to supplement the above discussion on instability.

\section{MECHANISMS OF LATERAL INSTABILITY}

In studying aspects of section instability, as evidenced in these tests, it is important to appreciate the orientation of a wall section and the adopted sign convention for loading or lateral displacements. These were summarized in Fig. 2. Also the stress- 
strain relationship in the vertical wall reinforcement pxior to buckling, shown in Fig. 20, and out of plane deformations, together with corresponding transverse strain patterns, shown in Fig. 21 must be correlated. Several distinct stages of the process of buckling of the flexural compression region of an inelastic wall section in the first storey may be identified as follows:

(a) At large negative ductilities, large tensile strains, such as shown at point $A$ of Fig. 20, are imposed on vertical bars near the east end of the wall. At this stage reasonably uniformiy spaced large approximately horizontal cracks extend across the thickness of the wall, as illustrated in Fig. 21 (a).

(b) In these tests, subsequent unloading, i.e. reduction of shear load, is accompanied by an increase of axial compression on the wall. When the tensile stresses in a particular bar reduces to zero (Point B in Fig. 20), sjgnificant residual tensile strains and hence wide cracks remain. Further reduction of shear load or the changing over to positive load will eventually produce compression stresses $f_{S, x}$ in all these bars. Unless the cracks, seen in Fig. 21(a), close, the entire internal. compression within the section must be resisted by reinforcement. Due to Bauschinger effect, the modulus of elasticity for steel, $E_{t}, x^{\prime}$ is reduced at this stage. point $X$ in Fig. 20 represents this state.

(c) Out of plane buckling (Fig. 2I(b)) may commence when the tangent modulus of steel, for example at point $C$ in Fig. 20, reaches a critically small vaiue, $E_{t, \text { crit, while residual concrete cracks are }}$ stili open.

Other important parameters of buckling are more complex. The effective length of a vertical wall strip for example will depend on the rotational restrajnt at the wall base and at first floor. The restraining effect of adjacent wall strips in the tension zone towards the west would also need to be quantified. Due to flexural loading on the wall, compression stresses and strains will vary with height. Therefore the tangent modulus of elasticity of steel will also vary in every bar with the distances from both the base and the east end of the section.

(d) If the horizontal cracks across the thickness of the wall (Fig. 21(c)) close before such a critical stage is reached (Point D in Fig. 20), concrete compression stresses will develop. This crack closure will gradually stiffen the section and transverse instability at that level of loading may be arrested.

(e) If buckling does occur, transverse displacements will be restricted

only if and when the affected part of the section can develop an adequate redistributed stress state. This must permit the resistance of internal forces from both lateral and axial loading of the wall and transverse moment due to out of plane eccentricity (Fig. $2 l(d)$ and (e)).
(E) If crack widths are still wide at the onset of instability, out of plane displacements may increase rapidly, even if internal vertical compression forces on the section are small. Wall 2 behaved in this manner.

(g) When only a small part of the wall tenas to buckle, because of lateral support afforded by other parts that are in tension, increase of axial and lateral load on the wall is possible without significant changes in transverse displacements. However, as positive ductility demands increase and hence concrete compression strains increase, the depth of compression, $\mathrm{c}$, in the section may also increase. This may be due to the combination of loss of cover, the decline in the resistance of the compressed concrete subjected to these higher strains, especially during repeated cycles with large ductility, and non-uniform strain distribution across the wall thickness due to out of plane displacements as shown in Fig. 21 (d) and (e). This increase of the neutral axis depth, c, may then lead to excessive compression strains in the unconfined part of the section with subsequent crushing of the concrete.

A comprehensive analytical solution to the problem of out of plane buckling was not consjdered to be possible because of several other factors, in addition to those Iisted in paragraph (g) above, that were judged to remain unquantified, such as:

(i) Small broken off concrete blocks or aggregate particles disturbed during tensile loading, as illustrated in Fig. 22, may prevent uniform closure of cracks upon load reversal.

(ii) Displacements caused by cyclic shear will cause random misfit of crack interfaces. The phenomenon may or may not trigger out of plane displacements.

(iii) The strain history of longitudinal reinforcement is a critical parameter of out of plane instability. Many cycles with moderate inelastic tensile strain demands may be sustained. without instability arising. On the other hand a single excursion with very large ductility may lead to instability during the immediately following load reversal.

(iv) The uneven spalling or loss of resistance of cover concrete may dictate the direction of out of plane movements.

(v) The resistance to transverse bending arising from out of plane eccentricity is a function of the square of wall thickness. Also it will depend on the thickness of the confined core, relative to the total wall thickness. This core thickness $(0.56 \mathrm{~b})$ was significantly less in these tests than what would be present $\left(\simeq 0.65 b_{w}\right)$ in prototype walls. 


\section{CONFINEMENT OF WALI SECTIONS}

The provision of confining reinforcement in the compression region of potential plastic hinge zone of a structural wall must address the two interrelated issues of area to be confined and quantity of hoops to be used.

\subsection{The Area of Wall Section to be}

As outlined in section 2.3 , current provisions (8) require one half of the theoretical depth of compression $(0.5 \mathrm{c})$ of the wall to be confined unless the neutral axial depth, $c$, is less than the critical value $C_{C}$, given by Eq. (1). It is evident, however, that compression strains in the unconfined region may also become excessive when, because of large ductility demands, the strains in the confined region become very large. At a displacement ductility of 4 concrete strains immediately adjacent to the confined core at the base of the wall, predicted from measurements, varied between 0.0086 and 0.011 in walls 1,3 and 4 , while strains in the confined outer zone were between 0.0175 and 0.0196

The steady monitoring of the variation of the neutral axis depth and concrete compression strains during the test provided some useful information that confirmed considerations based on first principles. However, experimental evidence was affected by a number of factors such as:

(i) Strain readings were made $300-500 \mathrm{~mm}$ above the theoretically critical base section.

(ii) In spite of the presence of large diagonal cracks, the variation of strain over the length, $b_{W}$, of the wall section was assumed to be linear.

(iii) As out of plane displacements commenced, variation of strains between the north and south face of the wall, become significant (Figs. 21 (d) and (e)). In such cases the computed mean strain across the wall thickness was used to predict strain gradients along the length of the wall section.

(iv) At large ductilities, the stage of major interest, some instrument readings became increasingly erratic.

As cyclic loading with increasing displacement amplitude progresses, the neutral axis depth must increase. This is partly due to the gradual reduction of the contribution of the cover concrete as well as that of the confined core to compression strength. Another cause is the out of plane bending of the compression zone of the section, as shown in Fig. 23. The average depth of compression in this case, $C_{a v}$ in Fig. 23(b), will be larger than that developed in the absence of lateral displacements, $c$, shown in Fig. $23(\mathrm{a})$.

These considerations indicate that the length of the confined region in a wall section, should, when necessary, be made larger than $0.5 \mathrm{c}$.
The strain profile (I) in Fig. 24 indicates the ultimate curvature, $\phi u$ " which might be necessary to enable the estimated displacement ductility, $\mu_{\Delta}$, for a particular structural wall to be sustained when the theoretical concrete strain in the extreme compression fibre reaches 0.004 . The value of the associated neutral axis depth, $\mathrm{c}_{c}$, could be estimated by Eq. (1), as outlined in section 2.2. To achieve in the wall the same ultimate curvature when the neutral axis depth, $c$, is larger than the critical value, $C_{C}$, as Fig. 24 shows, the length of section subjected to compression strains larger than 0.004 becomes $\alpha c$. It is therefore this length rather than $0.5 \mathrm{c}$ that should be confined. From the geometry shown in Fig. 24, $\alpha=1-\mathrm{c}_{\mathrm{C}} / \mathrm{c}$.

It is therefore suggested that, with some allowance for the previously reviewed factors that tend to increase the neutral axis depth, $c_{f}$ in walls beyond values derived from conventional section analysis, the length of confinement be derived from

$$
\alpha=1-0.7 c_{C} / c \geqq 0.5
$$

whenever $c_{c} / c<1$. When $c$ is only a little larger than $c_{C}$, a very small and impractical value of $\alpha$ would be obtained. In line with current recommendations (8), it is suggested that in such cases at least one half of the theoretical compression zone be confined, i.e. $a \geq 0.5$.

Based on $S=1.0$ and $\phi_{0}=1.56$, which would normaliy be used when $\mathrm{f}_{\mathrm{y}}^{\circ}=380 \mathrm{MPa}$, and measured concrete strengths, $f_{C}^{\prime}$, in Walls 2, 3 and 4 , in accordance with Eq. (4) approximately $70 \%$ of the compression block would need to be confined. In wall 1, $77 \%$ of $\mathrm{C}$ is indicated. Walls 3 and 4 as built satisfied this criterion, so no improvement in the performance of these two walls would be expected from the proposed requirement. It is likely, however, that the material compression failure in wall 1 could have been delayed had $\alpha=0.77$ been used. Wall 2 did not satisfy Eq. (4). Its failure, how.ever, was aue to instability at relatively low concrete strains rather than any lack of confinement.

\subsection{Quantity of Confinement}

Strains measured during the test in the east end hoops of the walls were generally below yield level even at $\mu_{\Delta}=6$. It is considered that the satisfactory performance obtained, prior to eventual concrete crushing in the units, indicates that both the quantity and the configuration of transverse hoop reinforcement was adequate. Hence no change in the existing code provisions (8), which in most cases are not onerous, are suggested.

7.

\section{CONCLUSIONS}

Structural walls expected to be subjected to large inelastic deformations during a design earthquake and tested in this series, exhibited very good energy dissipating properties. The transverse hoop reinforcement provided in accordance with code (8) requirements around the principal flexural bars, placed in the end regions of wall sections, were found to be adequate in preventing premature buckling 


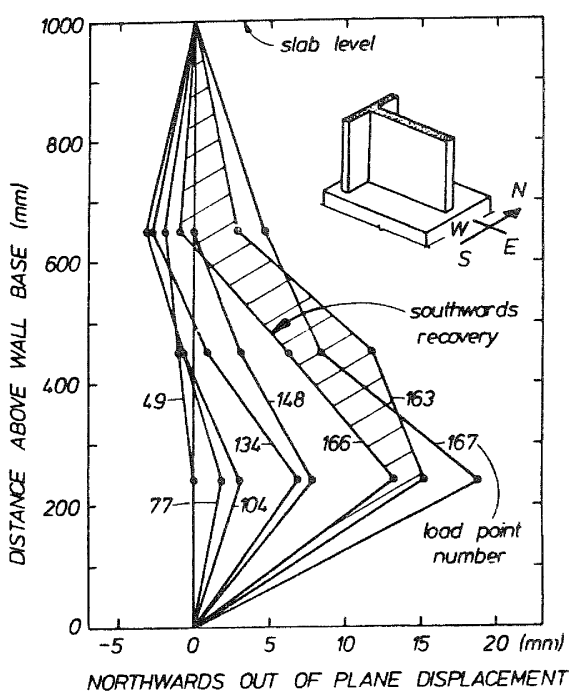

FIG. 19 Out of Plane Displacement Profiles - Wall 3

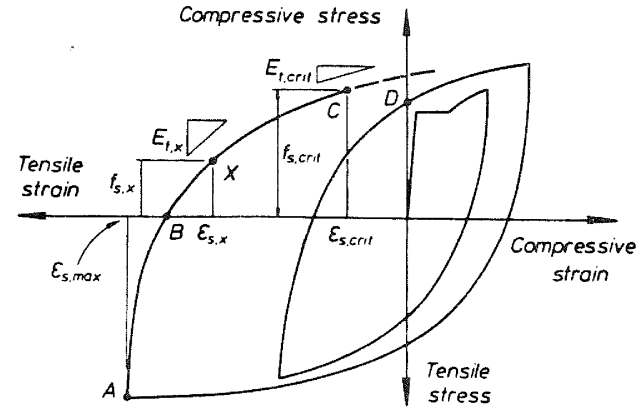

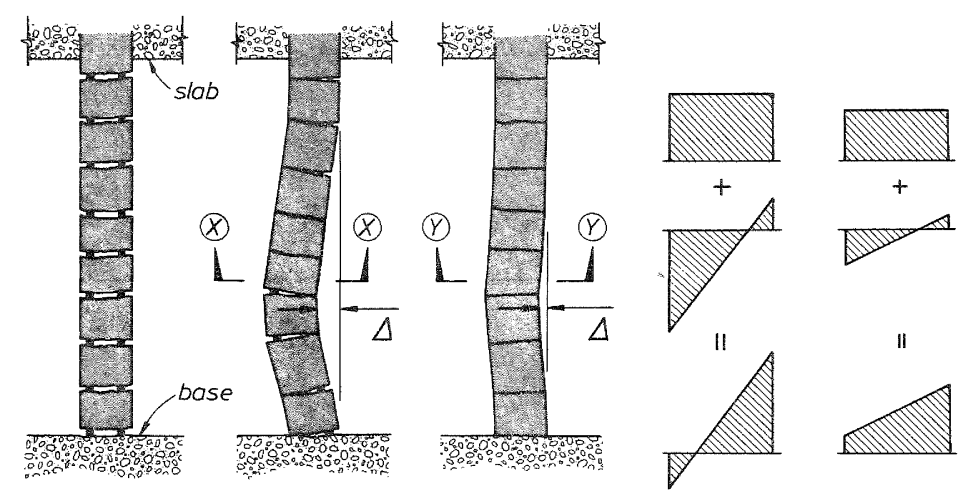

(a)

d) Strains at (e) Strains at section $X-X \quad$ section $Y-Y$

FIG. 21 Deformations and Strain Patterns in a Buckled Zone

(1)

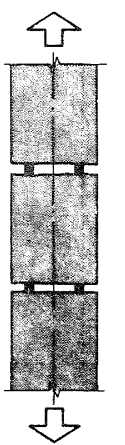

End zone in tension. Cracks are wide open.
(2)

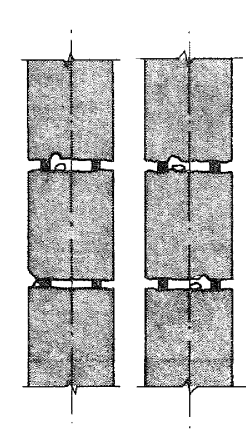

Small grains of aggregate partially block cracks.

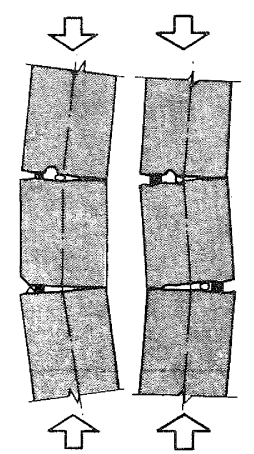

in zone of compression cracks close imperfectly initiating instability.
FIG. 20 Steel Stress-Strain Relationship Prior to Buckling
FIG. 22 The Effect of Dislocated Aggregate Particles on Wall Instability

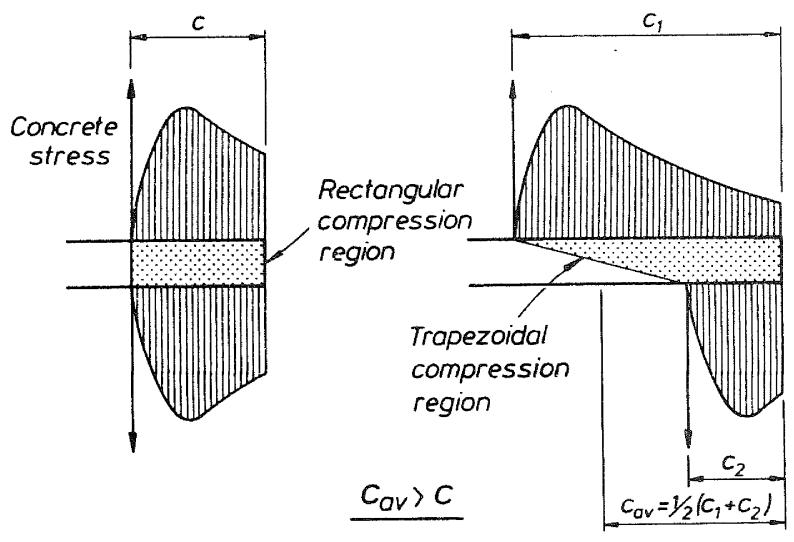

(a) No out of plane bending (b) Significant out of plane bending

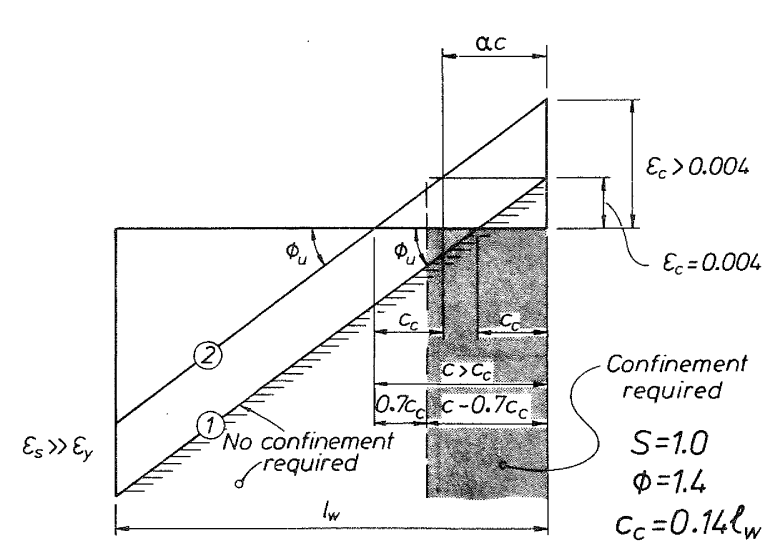

FIG. 23 Skewing of Wall Stress Distribution Due to out of Plane Bending
FIG. 24 Strain Patterns for Rectangular Wall Sections 
of those bars after the spalling of the cover concrete. Buckling of bars, as a primary cause of failure, was not observed in any of the tests.

The amount of transverse hoop reinforcement, required (8) to confine the concrete in the potential plastic hinge region, where the concrete is subjected to large compression strains, was also found to be satisfactory. Further research is likely to reveal that some reduction in the quantity of total hoop area may be possible without jeopardising good performance. Such a reduction, however, is likely to be of little economic significance.

Lateral displacements in the flexural compression zones were observed in all units under loads with large

ductilities. However, only one unit could be identified to have failed because of lateral instability. The important feature of this buckling failure was the relatively small applied lateral load when it occurred. The primary cause of such a failure at low load, is considered to be the extensive softening of the wall region in the plastic hinge zone, which was subjected to very large tensile strains during the immediately preceeding displacement cycle. In this project the effects of the unsupported height on the lateral instability of thin walls could not be studied in sufficient detail. It was considered, however, that the existing (8) limitation of $\mathrm{b} \geq \mathrm{h}_{\mathrm{w}} / 10$ is of the right order.

(5) Lateral displacements in the plastic hinge region of walls, when accompanied by large axial and flexural loads, were considered to have resulted in a softening also of parts of the section subjected to large compression strains. This, together with other effects that are responsible for the reduction of concrete strength during reversed cyclic loading, resulted in a redistribution of internal compression forces further away from the extreme compression fibre of the section, leading eventually to crushing of the concrete in the unconfined parts of the wall section.

(6) First principles were used to show where concrete compression strains in excess of 0.004 may occur, when large curvature ductility is required. With some allowance for the redistribution of internal compression forces in the potential plastic hinge region, it is recommended that a length of the wall section greater than currently specified (8) be provided with transverse confining hoop reinforcement.

While this type of material failure was always associated with sudden and dramatic loss of strength, contrary to what was observed in a primary instability failure, crushing in the unconfined region occurred after very large inelastic deformations. In the units that failed in this manner, displacements at the top of the order of 2 to $3 \%$ of the wall height were attained.
Because of more efficient confinement, reduced neutral axis depths and greater stiffness with respect to out of plane bending, the presence of compact boundary elements, such as flanges or barbells, will reduce or eliminate the causes of failures associated with lateral instability.

\section{ACKNOWLEDGEMENTS}

The work described, being part of a larger project, was generously assisted by financial grants from the Ministry of Works and Development and the University Grants Committee. The detailed work was carried out by W.J. Goodsir as part of his studies leading to the degree of Doctor of Philosophy, with the supervision of T. Paulay. The invaluable contributions of the University of Canterbury staff

P.G. Mitchell, G.W. Sim, G.E. Hill,

G.H. Clark, L.H. Gardner, Valerie Grey and Jocelyn $Y$. Johns are gratefully acknowledged.

\section{REFERENCES}

(1) SEAOC, "Recommended Lateral Force Requirements and Commentary" Seismology Committee, Structural Engineers' Association of California, San Francisco, 1973, 146pp.

Oesterle, R.G., et al, "Earthquake Resistant Structural Walls - Tests of Isolated Walls Appendix B - Test Results", Portland Cement Association, Skokie, 1976, 233pp.

Oesterle, R.G., ET AL, "Earthquake Resistant Structural Walls - Tests of Isolated Walls, Phase II", Portland Cement Association, Skokie. $1979,84 \mathrm{pp}$. plus appendices.

Vallenas, J.M., Bertero, V.V. and Popov, E.P., "Hysteretic Behaviour of Reinforced Concrete Structural Walls", Report UBC/EERC 79/20, Earthquake Engineering Research Center, University of California, Berkeley, 1979, 234pp.

Spurr, D.D., "Post Elastic Behaviour of Reinforced Concrete Frame-Wall Components and Assemblages Subjected to Simulated Seismic Loading", $\mathrm{Ph}$.D. Thesis, Department of Civil Engineering, University of Canterbury, New Zealand, 1984, 498pp.

(6) Park, R. and Paulay, T., "Reinforced Concrete Structures", John Wiley and Sons, New York, 1975, 769pp.

Paulay, T. and Williams, R.L., "The Analysis and Design of and the Evaluation of Design Actions for Reinforced Concrete Ductile Shear Wall structures", Bulletin of the New Zealand National Society for Earthquake Engineering, Vol. 13, No. 2 , June 1980, pp.108-143.

NZS 3101:1982, Parts 1 and 2, "Code of Practice for the Design of Concrete Structures", Standards Association of New Zealand, Wellington, 283pp. 
(9) NZS 4203:1976, "Code of Practice for General Structural Design and Design Loadings for Buildings", Standards Association of New Zealand. Wellington, $80 \mathrm{pp}$.

(10) Goodsir, W.J., "The Design of Coupled Frame-Wall Structures for Seismic Actions", Ph.D. Thesis, University of Canterbury, Christchurch, New Zealand, 1985, 385pp.

(11) ACI Committee 318, "Building Code Requirements for Reinforced Concrete", (ACI 318-77), American Concrete Institute, Detroit, 1977, 102pp.

(12) Park, R., Priestley, M.J.N. and Gill, W.G., "Ductility of Square Confined Concrete Columns", Journal of Structural Division, Proceedings of American Society of Civil Engineers, Vol. 108, No. ST4, April 1982, pp.929-950.

(13) Mander, J.B., "Seismic Design of Bridge Piers", Research Report 84-2, Department of Civil Engineering, University of Canterbury, New Zealand, 1984, $442 \mathrm{pp}$.

10. NOTATION

A

$=$ Gross area of section

= Area of tension reinforcement

= Area of concrete core extending over the outer half of the neutral axis depth which is subject to compression, measured to the outside of peripheral hoops

$A_{g}^{*}$

= Gross area of concrete section extending over outer half of the neutral axis depth which is subject to compression

$\mathrm{b}_{\mathrm{f}} \quad=$ Flange width for a tee section wall

$\mathrm{b}_{\mathrm{w}} \quad=$ width of web sustaining shear stress

c = Distance from extreme compression fibre to neutral axis

$\mathrm{c}_{\mathrm{C}} \quad=$ Critical value of $\mathrm{C}$

$\mathrm{E}_{\mathrm{S}} \quad=$ Modulus of elasticity for steel

$f_{\text {ult }}=$ Ultimate strength of reinforcement

$\mathrm{f}_{\mathrm{y}} \quad=$ Specified minimum yield strength of reinforcement

$\mathrm{f}_{\mathrm{yh}} \quad=$ Specified minimum yield strength of hoop reinforcement

$\mathrm{f}_{\mathrm{C}}^{\prime} \quad=$ Specified minimum 28 day concrete cylinder strength or Cylinder strength for experimental units at the time of testing

$\mathrm{h}_{\mathrm{w}} \quad=$ Height of a structural wall

h" $\quad=$ Dimension of concrete core of section measured perpendicular to the direction of the hoop leg, to the outside of the peripheral hoop $l_{n} \quad=$ clear height of wall

$\ell_{W} \quad=$ Major dimension of a structural wall section

$\mathrm{M}_{\text {code }}=$ Bending moment derived from code specified lateral seismic loading only

$\mathrm{M}^{\circ}=$ Overstrength moment capacity

$\mathrm{P}_{\mathrm{e}} \quad=$ Design axial force acting on a column during an earthquake

$\mathrm{s}_{\mathrm{h}}=$ spacing of transverse hoop sets

$\mathrm{S} \quad=$ Structural type factor

$\varepsilon_{\mathrm{C}}=$ Concrete compression strain

$\phi_{0} \quad=$ Flexural overstrength factor, defined as the ratio $\mathrm{MO} / \mathrm{M}_{\text {code }}$

$\phi_{\mathrm{u}} \quad=$ Ultimate curvature 